\title{
Transplantation of Ciliary Neurotrophic Factor-Expressing Adult Oligodendrocyte Precursor Cells Promotes Remyelination and Functional Recovery after Spinal Cord Injury
}

\author{
Qilin Cao, ${ }^{1,2,4}$ Qian He, ${ }^{1,2,4}$ Yaping Wang, ${ }^{1,2,6}$ Xiaoxin Cheng, ${ }^{1,2,4}$ Russell M. Howard, ${ }^{1,2}$ Yiping Zhang, ${ }^{1,2}$ \\ William H. DeVries, ${ }^{1,2}$ Christopher B. Shields, ${ }^{1,2,3}$ David S. K. Magnuson, ${ }^{1,2,3}$ Xiao-Ming Xu, ${ }^{1,2,3,5}$ Dong H. Kim, ${ }^{4}$ \\ and Scott R. Whittemore ${ }^{1,2,3}$ \\ ${ }^{1}$ Kentucky Spinal Cord Injury Research Center, and Departments of ${ }^{2}$ Neurological Surgery and ${ }^{3}$ Anatomical Sciences and Neurobiology, University of \\ Louisville School of Medicine, Louisville, Kentucky 40202, ${ }^{4}$ Department of Neurosurgery, University of Texas Medical School at Houston, Houston, Texas \\ 77030, ${ }^{5}$ Spinal Cord and Brain Injury Research Group, Stark Neurosciences Research Institute, and Department of Neurological Surgery, Indiana University \\ School of Medicine, Indianapolis, Indiana 46202, and ${ }^{6}$ Department of Anesthesiology, Second Xianya Hospital, Central South University Xianya Medical \\ School, Changsha, Hunan 410011, People's Republic of China
}

Demyelination contributes to the dysfunction after traumatic spinal cord injury (SCI). We explored whether the combination of neurotrophic factors and transplantation of adult rat spinal cord oligodendrocyte precursor cells (OPCs) could enhance remyelination and functional recovery after SCI. Ciliary neurotrophic factor (CNTF) was the most effective neurotrophic factor to promote oligodendrocyte (OL) differentiation and survival of OPCs in vitro. OPCs were infected with retroviruses expressing enhanced green fluorescent protein (EGFP) or CNTF and transplanted into the contused adult thoracic spinal cord $9 \mathrm{~d}$ after injury. Seven weeks after transplantation, the grafted OPCs survived and integrated into the injured spinal cord. The survival of grafted CNTF-OPCs increased fourfold compared with EGFP-OPCs. The grafted OPCs differentiated into adenomatus polyposis coli $\left(\mathrm{APC}^{+}\right) \mathrm{OLs}$, and CNTF significantly increased the percentage of $\mathrm{APC}^{+}$OLs from grafted OPCs. Immunofluorescent and immunoelectron microscopic analyses showed that the grafted OPCs formed central myelin sheaths around the axons in the injured spinal cord. The number of OL-remyelinated axons in ventrolateral funiculus (VLF) or lateral funiculus (LF) at the injured epicenter was significantly increased in animals that received CNTF-OPC grafts compared with all other groups. Importantly, 75\% of rats receiving CNTF-OPC grafts recovered transcranial magnetic motor-evoked potential and magnetic interenlargement reflex responses, indicating that conduction through the demyelinated axons in VLF or LF, respectively, was partially restored. More importantly, recovery of hindlimb locomotor function was significantly enhanced in animals receiving grafts of CNTF-OPCs. Thus, combined treatment with OPC grafts expressing CNTF can enhance remyelination and facilitate functional recovery after traumatic SCI.

\section{Introduction}

The pathophysiology and dysfunction after spinal cord injury (SCI) includes demyelination caused by oligodendrocyte (OL) cell death (Crowe et al., 1997; Liu et al., 1997; Li et al., 1999). Even after severe contusive SCI, demyelinated axons persist in the subpial rim of white matter in both humans (Bunge et al., 1993;

Received July 2, 2009; revised Nov. 9, 2009; accepted Dec. 26, 2009.

This work was supported by National Institutes of Health Grants NS061975 (Q.C.), NS054708 (S.R.W., D.S.K.M.), and RR15576 (Q.C., S.R.W., D.S.K.M.); The Institute for Rehabilitation and Research Foundation through Mission Connect (Q.C.); the Kentucky Spinal Cord and Head Injury Research Trust (Q.C., S.R.W.); and the Commonwealth of Kentucky Research Challenge for Excellence Trust Fund (S.R.W.). We thank Kim Fentress and Christian Nunn for their expert technical help. The statistical expertise of Darlene Burke and the highly skilled assistance of Cathie Caple are also gratefully acknowledged.

Correspondence should be addressed to Dr. Qilin Cao, Department of Neurosurgery, University of Texas Medical School at Houston, 6341 Fannin Street, MSE R158, Houston, TX 77030. E-mail: qi-lin.cao@uth.tmc.edu.

DOI:10.1523/JNEUROSCI.3174-09.2010

Copyright $\odot 2010$ the authors $\quad 0270-6474 / 10 / 302989-13 \$ 15.00 / 0$
Guest et al., 2005) and experimental animals (Blight, 1983, 1993; Cao et al., 2005a; Totoiu and Keirstead, 2005). Some remyelination by endogenous oligodendrocytes and invading peripheral Schwann cells occurs (Gledhill et al., 1973; Itoyama et al., 1983; Dusart et al., 1992; McTigue et al., 2001; Tripathi and McTigue, 2007). However, conduction deficits persist chronically in humans (Alexeeva et al., 1997, 1998) and rodents (Nashmi et al., 2000; Nashmi and Fehlings, 2001), suggesting spontaneous remyelination is limited and incomplete.

Multiple cell types have been grafted into the demyelinated spinal cord and remyelinate the demyelinated axons to varying degrees (Cao et al., 2002a; Kocsis et al., 2004). Neural stem cells (NSCs) and glial precursor cells have the potential to differentiate into OLs in vitro and in vivo. However, multipotent NSCs mainly differentiate into astrocytes after transplantation into the injured spinal cord (Chow et al., 2000; Shihabuddin et al., 2000; Cao et al., 2001; Wu et al., 2002; Vroemen et al., 2003; Hofstetter et al., 
2005). Such astrocyte differentiation from grafted NSCs may lead to allodynia (Hofstetter et al., 2005). Oligodendrocyte precursor cells (OPCs) may be optimal cell grafts because of their potential for more extensive remyelination and their lack of differentiation into astrocytes after transplantation. The adult CNS contains a significant number of OPCs (Wolswijk and Noble, 1989; Wolswijk et al., 1991; Roy et al., 1999; Chang et al., 2000; Horner et al., 2000). Although the turnover of these cells is relatively low under normal conditions, their proliferation increases significantly after SCI (Ishii et al., 2001; McTigue et al., 2001; Yamamoto et al., 2001) or multiple sclerosis (MS) (Wolswijk, 1998, 2000). More importantly, they can survive and differentiate into myelinating OLs after transplantation into demyelinated adult CNS (Zhang et al., 1999; Windrem et al., 2002, 2004).

Ciliary neurotrophic factor (CNTF) has neuroprotective effects on a variety of CNS and PNS neurons (Barbin et al., 1984; Hagg and Varon, 1993; Naumann et al., 2003). In addition, CNTF promotes OL differentiation and maturation from OPCs in vitro (Barres et al., 1996; Marmur et al., 1998; Stankoff et al., 2002). It also increases the survival of mature OLs (Barres et al., 1993; Louis et al., 1993). Importantly, CNTF and LIF (leukemia inhibitory factor) decrease the severity of experimental autoimmune encephalomyelitis by decreasing the OL apoptosis and enhancing OPC proliferation and differentiation (Butzkueven et al., 2002; Linker et al., 2002). These studies suggest a potential therapeutic role for CNTF in promoting remyelination by grafted or endogenous OPCs after injury. In this study, we have explored the potential of adult OPCs transplanted into the spinal cord to promote remyelination and functional recovery after traumatic SCI in rats. Our results indicate that CNTF increases the survival and differentiation of adult OPCs both in vitro and in vivo. Furthermore, transplantation of CNTF-expressing OPCs promotes remyelination and functional recovery after SCI.

\section{Materials and Methods}

All animal care and surgical interventions were undertaken in strict accordance with the Public Health Service Policy on Humane Care and Use of Laboratory Animals, Guide for the Care and Use of Laboratory Animals (Institute of Laboratory Animal Resources, National Research Council, 1996), and with the approval of the University of Louisville Institutional Animal Care and Use Committee and Institutional Biosafety Committee.

Isolation of OPCs from adult spinal cord. OPCs were immunopanned with an $\mathrm{O} 4$ antibody from the spinal cord of adult Fischer 344 rats that ubiquitously express human placental alkaline phosphatase (hPAP), as detailed previously (Talbott et al., 2006; Cheng et al., 2007). Briefly, the dissected spinal cords were minced into $1 \mathrm{~mm}^{3}$ pieces and incubated in HBSS containing $0.1 \%$ papain, $0.1 \%$ neutral protease, and $0.01 \%$ DNase for $30 \mathrm{~min}$ at $37^{\circ} \mathrm{C}$. The digestion was stopped by the addition of an equal volume of DMEM containing 20\% fetal bovine serum. Tissues were dissociated by repeated trituration with fire-polished Pasteur pipettes and were filtered through $70 \mu \mathrm{m}$ nylon mesh. The cells were incubated on an anti-RAN-2 antibody-coated dish for $30 \mathrm{~min}$ to deplete type 1 astrocytes and meningeal cells and then transferred to an O4-coated dish for $45 \mathrm{~min}$ to select OPCs. The purified OPCs on the dish were removed with trypsin and cultured in poly-L-lysine/laminin-coated dishes with DMEM/F12 medium containing $1 \times \mathrm{N} 2$ and $1 \times \mathrm{B} 27$ supplements, fibroblast growth factor 2 (FGF2) $(20 \mathrm{ng} / \mathrm{ml})$, platelet-derived growth factor aa (PDGFaa) $(10 \mathrm{ng} / \mathrm{ml})$, insulin $(5 \mu \mathrm{g} / \mathrm{ml})$, and BSA $(0.1 \%)$. Cells were fed with fresh growth medium every other day. In all cases, an aliquot of cells was analyzed the next day to determine the efficiency of the immunopanning. Only those cell preparations in which $>95 \%$ of the bound cells expressed O4 were used in the experiments.

Differentiation and survival of OPCs by growth factors in vitro. To determine which neurotrophic factor is most effective in promoting OL differentiation, adult OPCs were cultured in either basal media (DMEM/
F12 plus $1 \times \mathrm{N} 2$ plus $1 \times$ B27 plus $0.1 \%$ BSA) plus $5 \mathrm{ng} / \mathrm{ml} \mathrm{FGF2} \mathrm{without}$ (control) or with one of the following neurotrophic factors at concentration of $10 \mathrm{ng} / \mathrm{ml}$ for $3 \mathrm{~d}$ : neurotrophin 3 (NT3), CNTF, neuregulin (NRG), insulin-like growth factor-1 (IGF1), or glial cell line-derived growth factor (GDNF). All these neurotrophic factors have been shown previously to promote OL development. FGF2 was added to both groups to minimize spontaneous OPC differentiation. After $3 \mathrm{~d}$ of treatment, cell preparations were fixed and stained with antibodies for the more mature OL marker O1. The percentage of $\mathrm{O}^{+} \mathrm{OLs}$ was counted, and the differences among groups were analyzed by repeated-measures ANOVA followed by Tukey's honestly significant difference (HSD) post hoc $t$ tests using a 0.05 confidence interval. To examine the effect of neurotrophic factors on the survival of OLs, adult OPCs were induced to differentiate into $\mathrm{O}^{+}$OLs by withdrawal of FGF2 and PDGFaa for $2 \mathrm{~d}$. Then the differentiated OLs continued to grow in the basal medium alone or basal media with one of the above neurotrophic factors (all, $10 \mathrm{ng} / \mathrm{ml}$ ) for 5 more days. Cell survival was assessed either by an MTT colorimetric assay according to the manufacturer's instructions (Millipore Bioscience Research Reagents) or by counting the apoptotic $\mathrm{O}^{+}$OLs based on condensed and/or fragmental Hoechst-stained nuclei.

Immunofluorescence in vitro. To detect the surface membrane antigens, cells cultured on 24-well plates were incubated with primary antibodies A2B5, O4, or O1 (hybridoma supernatant, undiluted; American Type Culture Collection) at $4^{\circ} \mathrm{C}$ for $45 \mathrm{~min}$. After fixation with $4 \%$ paraformaldehyde, cells were incubated in FITC- or Texas Red-conjugated donkey anti-mouse IgM for $1 \mathrm{~h}$ at room temperature (RT). For recognition of other antigens, cells cultured on 24-well plates were fixed with $4 \%$ paraformaldehyde. Mouse monoclonal antibodies against $2^{\prime}, 3^{\prime}$-cyclic nucleotide phosphodiesterase (CNPase) (1:800; Covance), myelin basic protein (MBP) (1:50; Millipore Bioscience Research Reagents), or glial fibrillary acid protein (GFAP) (1:400; Sigma-Aldrich) were applied overnight at $4^{\circ} \mathrm{C}$. Then the appropriate fluorescence-conjugated secondary antibodies (1:200; Jackson ImmunoResearch Laboratories) were applied, and the nuclei were counterstained with DAPI $\left(4^{\prime}, 6^{\prime}\right.$-diamidino-2phenylindole). Controls were performed with the appropriate speciesspecific nonimmune sera and showed negligible background. Total cellular counts for each experimental well were obtained in 10 fields under $20 \times$ objective from three culture wells. The result for each experimental condition was verified a minimum of three independent times.

Cell preparation for transplantation. Enhanced green fluorescent protein (EGFP) and human CNTF cDNAs were cloned into the LZRS retroviral vector (Kinsella and Nolan, 1996). To generate high-titer virus, $\Phi N X$ cells (provided by Dr. Gary Nolan, Stanford University, Stanford, CA) were transfected using GenePorter II (Gene Therapy Systems), which routinely gave transfection efficiencies of $50-65 \%$. Selection with $2 \mu \mathrm{g} / \mathrm{ml}$ puromycin began $48 \mathrm{~h}$ later. To harvest viral supernatant, media was changed to the appropriate serum-free media without mitogens overnight and harvested the next day. We routinely obtain titers of $5 \times$ $10^{5}$ to $5 \times 10^{6} \mathrm{pfu} / \mathrm{ml}$. OPCs were treated with $1 \mu \mathrm{g} / \mathrm{ml}$ polybrene for $1 \mathrm{~h}$, followed by incubation in growth medium containing LZRS-EGFP or LZRS-CNTF-EGFP retrovirus for $4 \mathrm{~h}$. Routinely, $\sim 60 \%$ of the cells were labeled. Two hours before transplantation, the labeled cells were detached from the dishes using a cell lifter, collected by centrifugation at $1000 \times g$ for $4 \mathrm{~min}$, and resuspended in $1 \mathrm{ml}$ of culture medium. After cell count and viability assessment with trypan blue in a hemacytometer, the cell suspension was centrifuged a second time and resuspended in a smaller volume to give a density of $5 \times 10^{4}$ viable cells $/ \mu l$.

Surgical procedures. Surgical procedures were as described previously (Cao et al., 2001, 2002b, 2005a). Briefly, after anesthetization with Nembutal (50 mg/kg, i.p.), age- and weight-matched adult female Fischer 344 rats received a dorsal laminectomy at the ninth thoracic vertebral level (T9) to expose the spinal cord, and then a $150 \mathrm{kdyn}$ contusive SCI using the IH impactor (Infinite Horizons). At $8 \mathrm{~d}$ after injury, rats were randomly assigned to five groups, which received DMEM, EGFP-OPCs, CNTF-OPCs, EGFP-fibroblasts (FBs), or CNTF-FBs, respectively. Animals were reanesthetized as above, and the laminectomy site was reexposed. Four injections were made at $1 \mathrm{~mm}$ cranial to, caudal to, and left and right of the lesion at depth 1.3 and $0.6 \mathrm{~mm}$ laterally from midline. At each site, $2 \mu$ l of cell suspension or vehicle was injected through a glass 

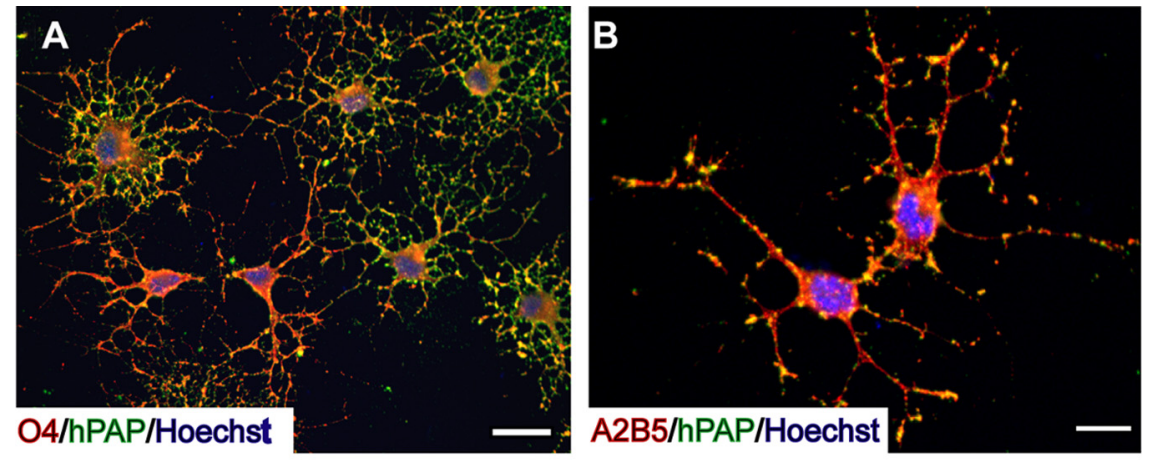

CNTF-OPCs, EGFP-OPCs, or DMEM, respectively, at four sites as described above. One week after transplantation, animals were killed with an overdose of Nembutal and $4 \mathrm{~mm}$ of spinal cord $(2 \mathrm{~mm}$ from the injured epicenter cranially and caudally, respectively) was used for protein isolation. Spinal cords were homogenized with cold lysis buffer as described above. After protein concentrations were calculated with the BCA protein assay, expression of CNTF in the injured spinal cord was detected by using the same ELISA assay as described above for OPCs.

Behavioral assessment. Open-field locomo-
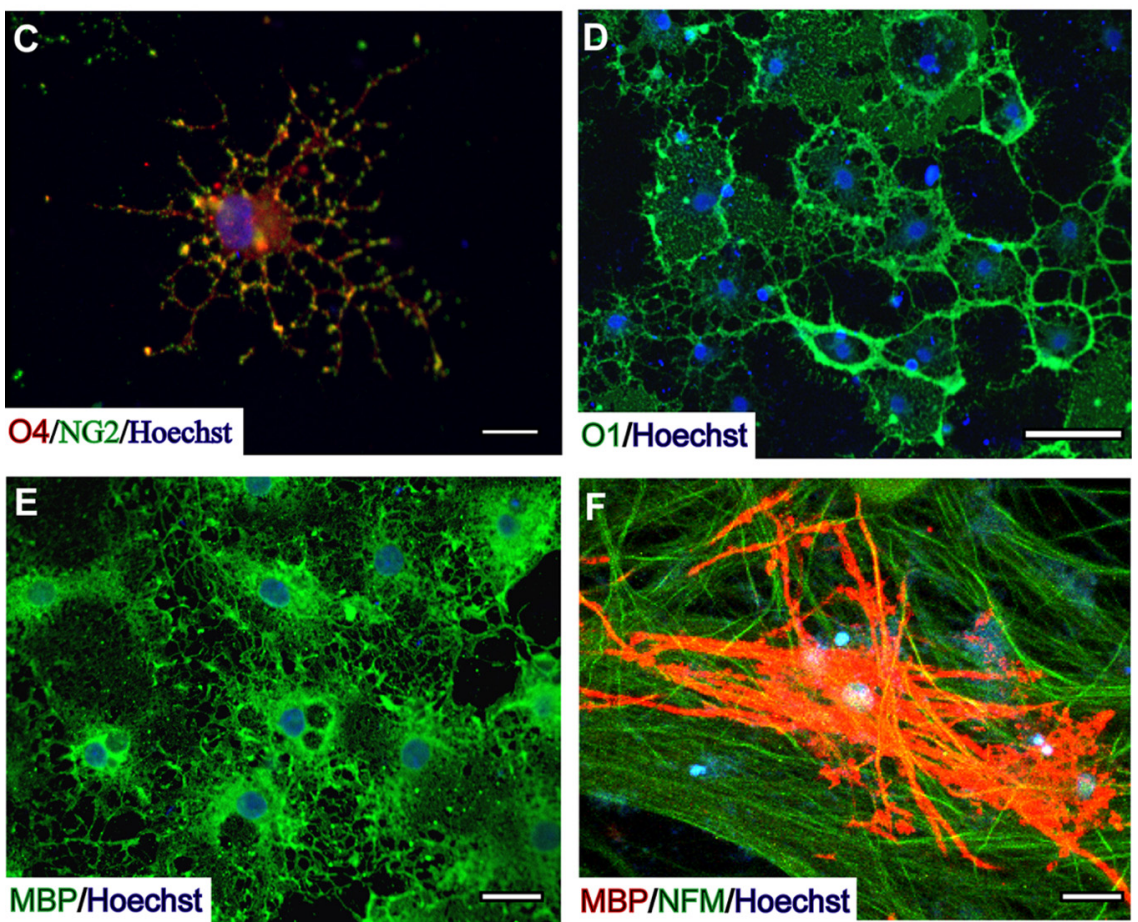

tor testing using the Basso-Beattie-Bresnahan (BBB) locomotor rating scale (Basso et al., 1995) was performed at day 7 after injury and once weekly thereafter for 7 weeks after injury. All the animals were coded and behavioral assessments were performed by two investigators blinded with respect to the treatment groups. The mean BBB scores were tallied by injured groups and plotted as a function of time after injury. Changes in BBB scores over time for the five groups were analyzed using repeatedmeasures ANOVA with the between-groups factor. Differences among the groups and each group over the 7 postinjury test weeks were performed using Tukey's HSD post hoc $t$ tests.

Electrophysiological assessment of spinal cord function. The methods for evaluating transcranial magnetic motor-evoked potential (tcMMEP) and magnetic interenlargement reflex (MIER) responses were described in detail in previous studies (Loy et al., 2002; Cao et al., 2005a,b; Beaumont et al., 2006). Briefly, tcMMEPs were recorded preoperatively and every other week postoperatively in restrained, unanesthetized rats as a means to evaluate conduction through long descending motor pathways. The tcMMEP system used a MagStim 200 magnetic stimulator attached to a $50-\mathrm{mm}$ diameter transducer coil (Magstim) and recorded using a Cadwell Sierra II data acquisition system. The transducer was placed over the skull, and a short $(70 \mu \mathrm{s})$ magnetic pulse was delivered while EMG responses were recorded from hindlimb flexor (tibialis anterior) and ex-

micropipette with an outer diameter of $50-70 \mu \mathrm{m}$ and the tip sharpbeveled to $30-50^{\circ}$ at rate of $0.5 \mu \mathrm{l} / \mathrm{min}$ as described previously (Cao et al., 2001, 2002b). Thus, a total of 400,000 cells was grafted into each injured spinal cord. The animals were allowed to survive 8 weeks after transplantation.

ELISA assessment of CNTF expression. To detect the expression of CNTF in the cultured OPCs in vitro, OPCs were infected with EGFP or CNTF retroviruses. Two days later, the uninfected, EGFP- or CNTFOPCs were harvested with cold lysis buffer consisting of $137 \mathrm{~mm} \mathrm{NaCl}, 20$ $\mathrm{mm}$ Tris- $\mathrm{HCl}, 1 \% \mathrm{NP}-40$, and $1 \times$ protease inhibitor mixture set III (Calbiochem). Protein concentrations were calculated with the BCA protein assay (Pierce). Expression of CNTF was examined by commercially available sandwich technique ELISA kit (R\&D Systems) following the manufacturer's recommended protocol. Oxidized horseradish peroxidase enzymatic products in the microplate wells were read at $450 \mathrm{~nm}$ absorbance using a SpectraMax Plus 384 plate reader (Molecular Devices). Differences of CNTF expression among three groups was compared with repeated-measures ANOVA, followed by Student-Newman-Keuls post hoc test. The level of statistical significance was set at $p<0.05$. To detect the expression of CNTF in the injured spinal cord, a total of nine animals received $150 \mathrm{kdyn} \mathrm{IH}$ contusion SCI as described above. Eight days later, they were then randomly divided into three groups that received $8 \mu \mathrm{l}$ of tensor (gastrocnemius) muscles with single needle electrodes.

MIER responses were used as a means to evaluate conduction of long, interenlargement ascending propriospinal axons. Also recorded from unanesthetized animals, EMGs from the triceps muscle after magnetic stimulation of the contralateral hindlimb were recorded in response to magnetic stimulation (single or paired with a $1 \mathrm{~ms}$ separation) of the sciatic nerve in one hindlimb by placing a dual $25 \mathrm{~mm}$ figure eight coil (Magstim) over the hip and proximal femur. Both amplitudes and latencies of tcMMEP and MIER responses were analyzed by random and fixed-effects model with repeated-measures ANOVA followed by the appropriate post hoc $t$ tests using a 0.05 confidence interval.

Immunohistochemistry. For the histological analysis of the grafted cells, rats were anesthetized with $80 \mathrm{mg} / \mathrm{kg}$ Nembutal and perfused transcardially with $0.01 \mathrm{~m}$ PBS, $\mathrm{pH} 7.4$, followed by $4 \%$ paraformaldehyde in $0.01 \mathrm{~m}$ phosphate buffer $(\mathrm{PB})$. The spinal cord segments that received the grafts were removed, cryoprotected in 30\% sucrose buffer overnight at $4^{\circ} \mathrm{C}$, and embedded in OCT compound. Some cords were transversely sectioned at $16 \mu \mathrm{m}$ on a cryostat, whereas others were cut longitudinally. After blocking with 10\% donkey serum in Tris-buffered saline (TBS) containing $0.3 \%$ Triton X-100 (TBST) for $1 \mathrm{~h}$ at room temperature (RT), the sections were incubated in TBST containing 5\% donkey serum, poly- 
clonal chicken anti-GFP (1:500; Millipore Bioscience Research Reagents) or polyclonal rabbit anti-neurofilament M (NFM) (a marker for axons; 1:200; Millipore Bioscience Research Reagents) with one of the following monoclonal mouse antibodies: anti-MBP (a marker for myelin; 1:50; Millipore Bioscience Research Reagents), anti-GFAP (a marker for astrocytes; 1:100; Millipore Bioscience Research Reagents), anti-adenomatus polyposis coli (APC) (also called CC1; a marker that labels cell bodies of mature OL) (1:200; BD Pharmingen), antiNG2 (a marker for OPCs; 1:200; Millipore Bioscience Research Reagents), or anti-nestin (a marker for undifferentiated NSCs or progenitor cells; $1: 10$; DSHB) overnight at $4^{\circ} \mathrm{C}$. After three washes of $10 \mathrm{~min}$ in TBS, sections were incubated in TBST containing 5\% donkey serum, donkey anti-sheep or donkey anti-chicken FITCconjugated Fab' fragments (1:100), donkey antimouse Texas Red-conjugated Fab' fragments (1:200), or donkey anti-rabbit AMCA (aminomethyl-coumarin-acetate)-conjugated Fab' fragments (1:100; Jackson ImmunoResearch Laboratories) for $1 \mathrm{~h}$ at RT. The sections were rinsed in TBS and coverslipped with antifade mounting medium (Invitrogen). A Nikon Eclipse TE300 inverted fluorescence microscope equipped with RT color Spot camera or a Zeiss Axiophot, LSM 510 confocal microscopy was used to capture representative images. Photomicrographs were assembled using Adobe Photoshop and Adobe Illustrator software.

To determine the differentiation of grafted EGFP- or CNTF-OPCs in the injured spinal cord, four coronal sections, $200 \mu \mathrm{m}$ apart, were taken spanning the lesion epicenter. The percentage of engrafted OPCs (either EGFP- or CNTF-infected, identified by EGFP expression) that coexpressed APC was quantified for the two groups of grafted animals. For ratio analysis, unbiased stereological counting methods are not needed (Coggeshall and Lekan, 1996).

Quantification of axonal density and remyelination. High-precision design-based unbiased systematic random sampling technique (Storkebaum et al., 2005) was used to quantify the number of normally myelinated, OL- or Schwann cell-remyelinated axons in the ventrolateral funiculus (VLF) and lateral funiculus (LF) where tcMMEP and MIER responses are carried, respectively. Three representative toluidine bluestained $1 \mu \mathrm{m}$ semithin cross sections at the injured epicenter were used for each animal. To obtain accurate counts without relying on densities or introducing shrinkage bias, geometrical anatomy in the injured spinal cord was used to define the VLF and LF (Casley-Smith, 1988). The whole spinal cords on toluidine blue-stained $1 \mu \mathrm{m}$ semithin cross sections were traced with an Olympus BX60 microscope attached to a stereology workstation (StereoInvestigator; MicroBrightField) at $120 \times$ magnification. This outer trace was then partitioned into eight equal segments. The center of each section was determined by the intersection of two digitally imposed lines that connected any point to its opposite point. The VLF was defined by connecting the points in the anterior median fissure, the point directly lateral to the anterior medial fissure, and the center point. The LF was defined by connecting the points immediately lateral to the anterior median fissure, the point immediately lateral to the dorsal center, and absolute center point. The VLF and LF at each representative section were divided into counting frames of 25 by $25 \mu \mathrm{m}$ using the Optical Fractionator probe of the software StereoInvestigator at $120 \times$ magnification. The scan grid size was anticipated to be $250 \times 250 \mu \mathrm{m}$, allowing for an area-sampling fraction (ASF) of $1 / 100$ (the scan grid size and ASF were determined by the software with a Schmitz-Hof coefficient of error $<0.10$ ). The scan grid orientation was randomly rotated since the spinal cords were non-isotropically cut. The number of normally myelinated and OL- or Schwann cell-remyelinated axons were counted in the sampling area at $3000 \times$ magnification using an oil-immersion objective with a high numerical aperture ( $100 \times$; oil; numerical aperture, 1.00 ) by a investigator who was blinded to the animal groups. The axon counts of each category in all sampling areas in the defined VLF or LF of each section were multiplied by the sampling probability to give an estimate of the total number of axons of each category within VLF or LF as described previously (Schmitz and Hof, 2000). The numbers from the three sections at the epicenter were averaged. The difference between the axon number in each category in the VLF or LF among groups was analyzed with repeated-measures ANOVA followed by the appropriate post hoc $t$ tests using a 0.05 confidence interval.

Electron microscopic immunocytochemistry. For immuno-EM, rats were perfused with the same perfusion fixatives as described above for immunohistochemistry but with addition of $0.1 \%$ glutaraldehyde. After perfusion, the spinal cord was carefully dissected out and blocked into proximal (injured epicenter) and distant ( $8 \mathrm{~mm}$ away from the epicenter) segments in both caudal and rostral directions. Horizontal sections were cut at $40 \mu \mathrm{m}$ on a vibratome. The sections were subjected to immunohistochemical processing for hPAP using the avidin-biotin peroxidase complex (ABC) method. Briefly, sections were blocked in $10 \%$ goat serum in $0.01 \mathrm{M}$ PBS containing $0.05 \%$ Triton X-100 for $30 \mathrm{~min}$ at RT and then incubated with polyclonal rabbit anti-hPAP antibody (1:2000; Millipore Bioscience Research Reagents) containing 3\% goat serum for $24 \mathrm{~h}$ at $4^{\circ} \mathrm{C}$. After several rinses in $0.01 \mathrm{M}$ PBS, the sections were reacted with biotinylated goat anti-rabbit IgG (1:200; Vector Laboratories) for $1 \mathrm{~h}$ and subsequently with Vector ABC reagent (1:200; Vector Laboratories) for $1 \mathrm{~h}$ at RT. The reaction product was revealed by incubation for $5-10 \mathrm{~min}$ with $0.05 \%$ diaminobenzidine tetrahydrochloride (DAB) and $0.01 \%$ $\mathrm{H}_{2} \mathrm{O}_{2}$ in $0.05 \mathrm{M}$ Tris- $\mathrm{HCl}, \mathrm{pH}$ 7.6. After reaction, the sections were postfixed in $1 \%$ osmium tetroxide in $0.1 \mathrm{M} \mathrm{PB}, \mathrm{pH} 7.4$, for $1 \mathrm{~h}$ at RT and dehydrated in graded ethanols and propylene oxide. The sections were then flat-embedded in Epon on slides. After cutting, sections were examined and the VLF was cut out and glued to Epon cylinders for ultrathin sectioning. The ultrathin sections were mounted on grids and examined and photographed using a Philips CM10 transmission electron microscope. 

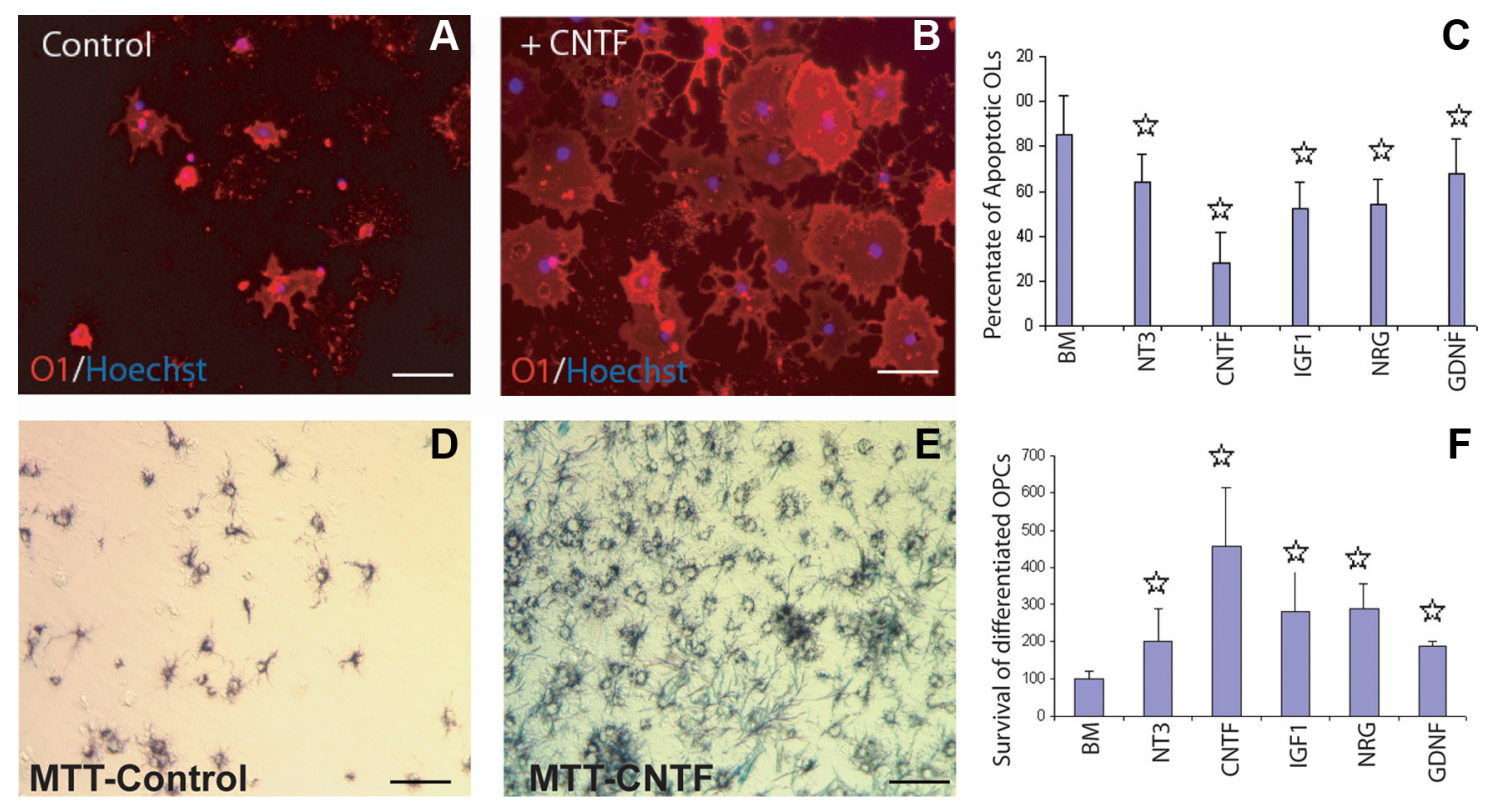

Figure 3. CNTF significantly increased OL survival and maturation in vitro. Adult OPCs were differentiated for $2 \mathrm{~d}$ in basal medium (BM) to become $01^{+} 0 \mathrm{Ls}$ and continued to mature for 5 more days in BM plus the indicated growth factor. Without additional trophic support, most OLs underwent apoptosis ( $\boldsymbol{A}$ ). Addition of CNTF prevented most OLs from initiating apoptosis ( $\boldsymbol{B}$ ). The surviving OLs showed mature $0 \mathrm{~L}$ morphology with complex membrane sheets. Although all tested growth factors protected differentiated $0 \mathrm{Ls}$ from death, (NTF was the most effective (C). The survival of $0 \mathrm{Ls}$ was also measured by MTT $(\boldsymbol{D}-\boldsymbol{F})$. Compared with control BM $(\boldsymbol{D})$, there was significantly more survival with all growth factors, but CNTF was the most effective $(\boldsymbol{E}, \boldsymbol{F})$. Data in $\boldsymbol{C}$ and $\boldsymbol{F}$ represent the mean \pm SD $(n=4)$. ${ }^{2} p<0.05$. Scale bars: $\boldsymbol{A}, \boldsymbol{B}, 25 \mu \mathrm{m} ; \boldsymbol{D}, \boldsymbol{E}, 50 \mu \mathrm{m}$.

\section{Results}

Isolation, expansion, and characterization of OPCs from adult spinal cord

All isolated OPCs expressed hPAP (Fig. 1A,B). More importantly, $>95 \%$ of these cells expressed the OPC-specific markers 04 (Fig. 1A), A2B5 (Fig. 1B), or NG2 (Fig. 1C). Less than 10\% of adult OPCs expressed the more mature oligodendrocyte-specific marker O1 (data not shown). Adult OPCs were not labeled by antibodies recognizing the mature oligodendrocyte-specific proteins MBP and PLP (proteolipid protein) or the astrocyte-specific proteins GFAP and vimentin (data not shown). Adult OPCs proliferated in culture medium containing FGF2 and PDGFaa for multiple passages (at least 10) in vitro without changing phenotype (Cheng et al., 2007). To test their differentiation potential, adult OPCs were induced to differentiate by withdrawing FGF2 and PDGFaa. When cultured in serum-free medium containing insulin and CNTF but lacking FGF2 and PDGFaa for $3 \mathrm{~d},>85 \%$ of cells expressed $\mathrm{O} 1$ and developed the typical, highly processbearing morphology of OLs (Fig. 1D). Moreover, over $6 \mathrm{~d}$ of differentiation, $>80 \%$ of the cells developed into mature $\mathrm{MBP}^{+}$ OLs with visible membrane sheets (Fig. $1 E$ ). To further test their capacity to myelinate axons in vitro, adult OPCs were cocultured with purified embryonic dorsal root ganglion (DRG) neurons (Plant et al., 2002; Cao et al., 2005b). After coculture for 2 weeks, adult OPCs were observed to myelinate the DRG axons as assessed by MBP expression (Fig. $1 F$ ). These results demonstrate that adult OPCs have the capacity to differentiate into mature oligodendrocytes to myelinate axons in vitro. Whereas no astrocytic differentiation was observed in the differentiation medium without serum, $>60 \%$ of adult OPCs differentiated into $\mathrm{GFAP}^{+}$ astrocytes after differentiation in the same medium with $10 \%$ FBS (Cheng et al., 2007). These astrocytes also expressed A2B5 with the typical stellate morphology of type 2 astrocytes. These results showed that adult OPCs from the spinal cord were bipotential with the capacity to differentiate into oligodendrocytes in the absence of serum and into type 2 astrocytes in the presence of serum, similar to their perinatal counterparts (Raff et al., 1983).

\section{Differentiation and survival of adult OPCs induced by growth} factors in vitro

A substantial number of growth factors play critical roles in the regulation of OPC differentiation, maturation, and survival during CNS development. Their effects on adult OPCs have not been well investigated. We examined whether OL differentiation of adult OPCs could be promoted by the growth factors NT3, CNTF, IGF1, NRG, or GDNF, all having been previously shown to regulate OL development. Adult OPCs were differentiated for $5 \mathrm{~d}$ in basal medium with $5 \mathrm{ng} / \mathrm{ml} \mathrm{FGF} 2$ plus one growth factor (10 ng/ml). Our previous study showed that adult OPCs spontaneously differentiated into OLs after withdrawal of mitogens FGF2 and PDGFaa (Cheng et al., 2007). Hence, addition of FGF2 $(5 \mathrm{ng} / \mathrm{ml})$ prevented the spontaneous differentiation. After culture for $3 \mathrm{~d}$ in basal medium containing $5 \mathrm{ng} / \mathrm{ml} \mathrm{FGF2} \mathrm{but} \mathrm{with-}$ out growth factor, $17 \%$ of OPCs differentiated into $\mathrm{O} 1^{+} \mathrm{OLs}$ (Fig. 2A,D). After differentiation with CNTF (Fig. 2B), IGF1 (Fig. 2C), NT3, NRG, or GDNF, the percentages of $\mathrm{O} 1^{+} \mathrm{OLs}$ were $41,40,18,22$, and 29, respectively (Fig. 2D). Addition of CNTF or IGF1 significantly increased the percentage of $\mathrm{O} 1^{+} \mathrm{OLs}$ compared with the control cultures without growth factor (all $p<0.05)$.

We further tested whether these growth factors could promote the survival of differentiated OLs. Adult OPCs were induced to differentiate into $\mathrm{O}^{+}$OLs by withdrawal of FGF2 and PDGFaa for $2 \mathrm{~d}$. The differentiated OLs were subsequently grown for $5 \mathrm{~d}$ in basal medium alone or with NT3, CNTF, IGF1, NRG, or GDNF $(10 \mathrm{ng} / \mathrm{ml})$. In basal medium, $85 \%$ of OLs were apoptotic (Fig. $3 A, C$ ). The membrane sheets in these OLs were broken and lost (Fig. 3A). However, the majority of OLs in the CNTF cultures survived (Fig. $3 B, C$ ). These OLs had an extensive membrane sheet, a typical in vitro morphology of mature OLs (Fig. $3 B$ ). The 
percentage of apoptotic OLs in the cultures with CNTF, NT3, IGF1, NRG, or GDNF was 28, 65, 52, 54, 68\%, respectively (Fig. 3C), all being significantly decreased compared with $85 \%$ in basal medium. The number of surviving OLs, assessed by MTT staining, was much higher in the cultures with CNTF than in control cultures (Fig. 3D,E). The total number of OLs in the cultures with CNTF, NT3, IGF1, NRG, or GDNF was $4.6,2,2.8,2.9$, or 1.9 times greater than that seen in the control cultures, respectively (Fig. $3 F$ ) (all $p<0.01$ ). Therefore, among all these tested growth factors, CNTF was the most effective in promoting the survival and differentiation of adult OPCs.

\section{Transplanted OPCs survive and} migrate within the injured spinal cord We next asked whether adult OPCs would survive and integrate into the injured spinal cord after transplantation. We further examined whether expression of CNTF would promote the survival and differentiation of grafted OPCs in the injured spinal cord. We infected $\mathrm{hPAP}^{+} \mathrm{OPCs}$ with retroviruses expressing either EGFP or CNTF before transplantation. Two days after infection, $>70 \%$ of OPCs expressed EGFP or CNTF (Fig. 4A). The expression of CNTF in the infected OPCs was confirmed by ELISA (Fig. $4 \mathrm{~B}$ ). The concentration of CNTF in CNTF-OPCs is fivefold increased compared with the uninfected or EGFP-OPCs at $2 \mathrm{~d}$ after infection. To further examine whether CNTF-OPCs could stably express CNTF in the injured spinal cord after transplantation, we grafted CNTF-OPCs into the injured spinal cord at $8 \mathrm{~d}$ after SCI and then detected their expression of CNTF by immunohistochemistry and ELISA 1 week later. As shown in Figure $4 C$, the grafted CNTF-OPCs retained their expression of CNTF in vivo 1 week after transplantation. Our ELISA also showed that expression of CNTF in animals that received grafts of CNTF-OPCs was significantly higher compared with ones that received grafts of DMEM or EGFP-OPCs at 1 week after transplantation (2 weeks after injury) (Fig. 4D). These results demonstrated that expression of CNTF was significantly increased in CNTF-OPCs both in vitro and in vivo. We next tested the effects of CNTF expression on the long-term survival of grafted OPCs in the injured spinal cord. The survival of grafted OPCs was identified by hPAP immunoreactivity at 7 weeks after transplantation. As shown in Figure 4, robust survival of transplanted OPCs was observed in CNTF-OPC-grafted animals $(E-G)$ and also EGFP-OPC-grafted animals (data not shown). Surviving OPCs distributed around the cavities and integrated into the spared spinal cord paren-
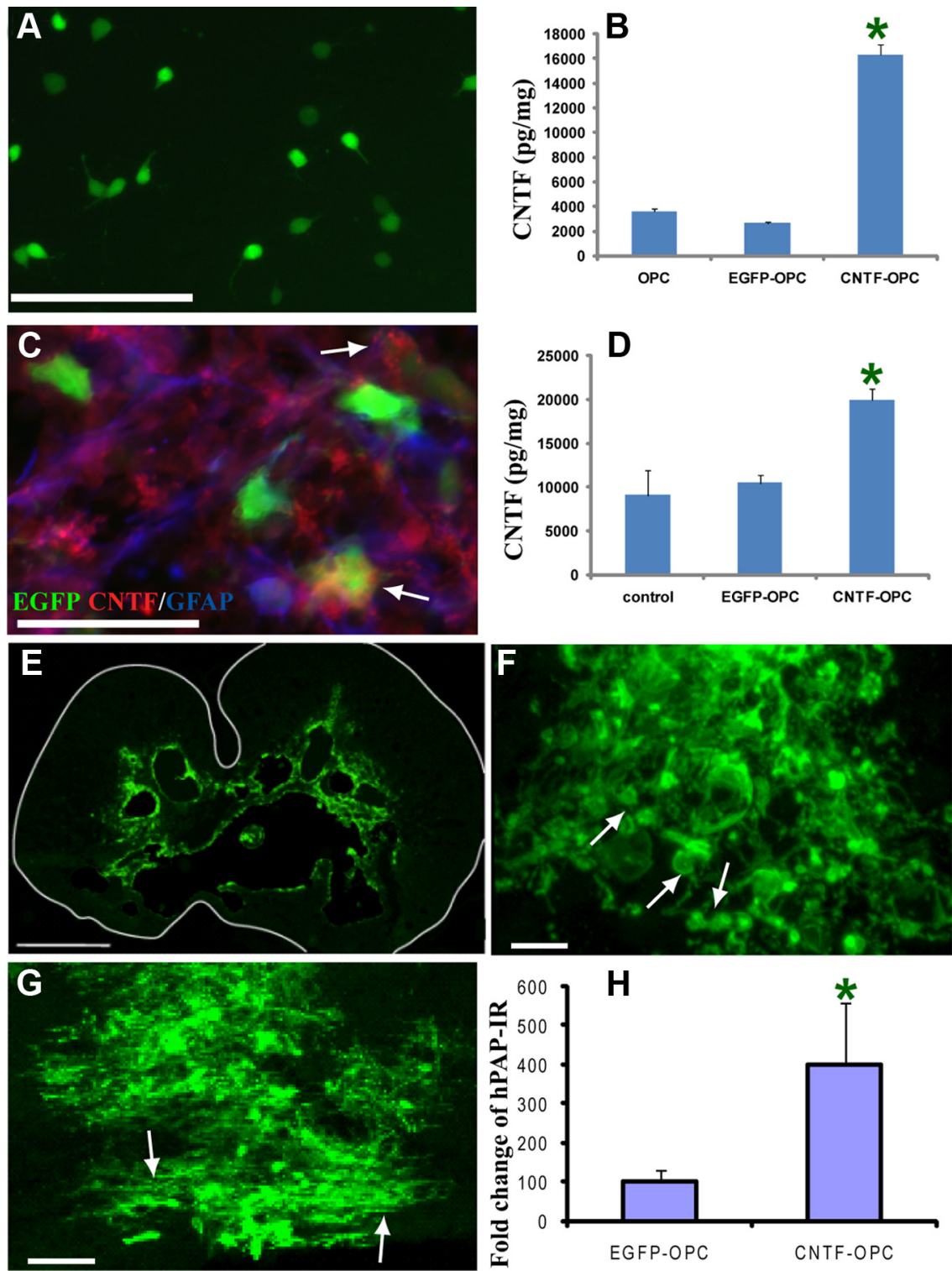

Figure 4. CNTF promoted the survival of grafted OPCs after SCI. Adult OPCs were infected with retroviruses to express EGFP or CNTF. At 2 d after infection, $>70 \%$ of OPCs were infected $(\boldsymbol{A})$. Importantly, expression of CNTF in CNTF-OPCs was significantly higher compared with uninfected or EGFP-OPCs by ELISA $(\boldsymbol{B})$. One week after transplantation, CNTF-OPCs continued to express CNTF in the injured spinal cord ( $\boldsymbol{C}$, arrows). The ELISA showed that CNTF concentrations in the injured spinal cord from animals receiving grafted CNTF-OPCs were significantly higher than animals receiving DMEM, or EGFP-OPCS (D). The effects of CNTF expression on the long-term survival of grafted OPCs were detected by hPAP immunohistochemistry. At 2 months after transplantation, robust graft survival was observed for both CNTF- $(\boldsymbol{E}-\boldsymbol{G})$ or EGFP-OPCS (data not shown). At higher magnification, the hPAP-immunoreactive processes formed ring-like structures that were evident in cross sections $(\boldsymbol{F})$ and sheath-like structures readily apparent in longitudinal sections $(\boldsymbol{G})$. The survival and process elaboration from the grafted OPCS, measured by hPAP immunoreactivity, was four time greater in CNTF-OPCs compared with EGFP-OPCs (D), indicating that expression of CNTF promoted the survival of grafted OPCs after SCI. Data in $\boldsymbol{B}, \boldsymbol{D}$ and $\boldsymbol{H}$ represent the mean $\pm \mathrm{SD}(n=3$ in $\boldsymbol{B}$ and $\boldsymbol{D}$ and 6 in $\boldsymbol{H})$. ${ }^{*} p<0.05$. Scale bars: $A, C, 50 \mu \mathrm{m} ; \boldsymbol{E}, 500 \mu \mathrm{m} ; \boldsymbol{F}, \boldsymbol{G}, 20 \mu \mathrm{m}$.

chyma in the injured epicenter (Fig. 4E). The hPAP-immunoreactive processes from grafted OPCs formed ring structures in cross sections (Fig. $4 F$, arrows) and sheaths along axons in longitudinal sections (Fig. 4G, arrows).

To further examine whether expression of CNTF could increase the survival of the grafted OPCs in the injured spinal cords, we quantified the total volume of hPAP immunoreactivity in animals that received EGFP-OPC or CNTF-OPC grafts at 7 weeks after transplantation. The average volume of hPAP immunoreactivity in CNTF-OPC-grafted animals was $0.23 \mathrm{~mm}^{3}$, which was 

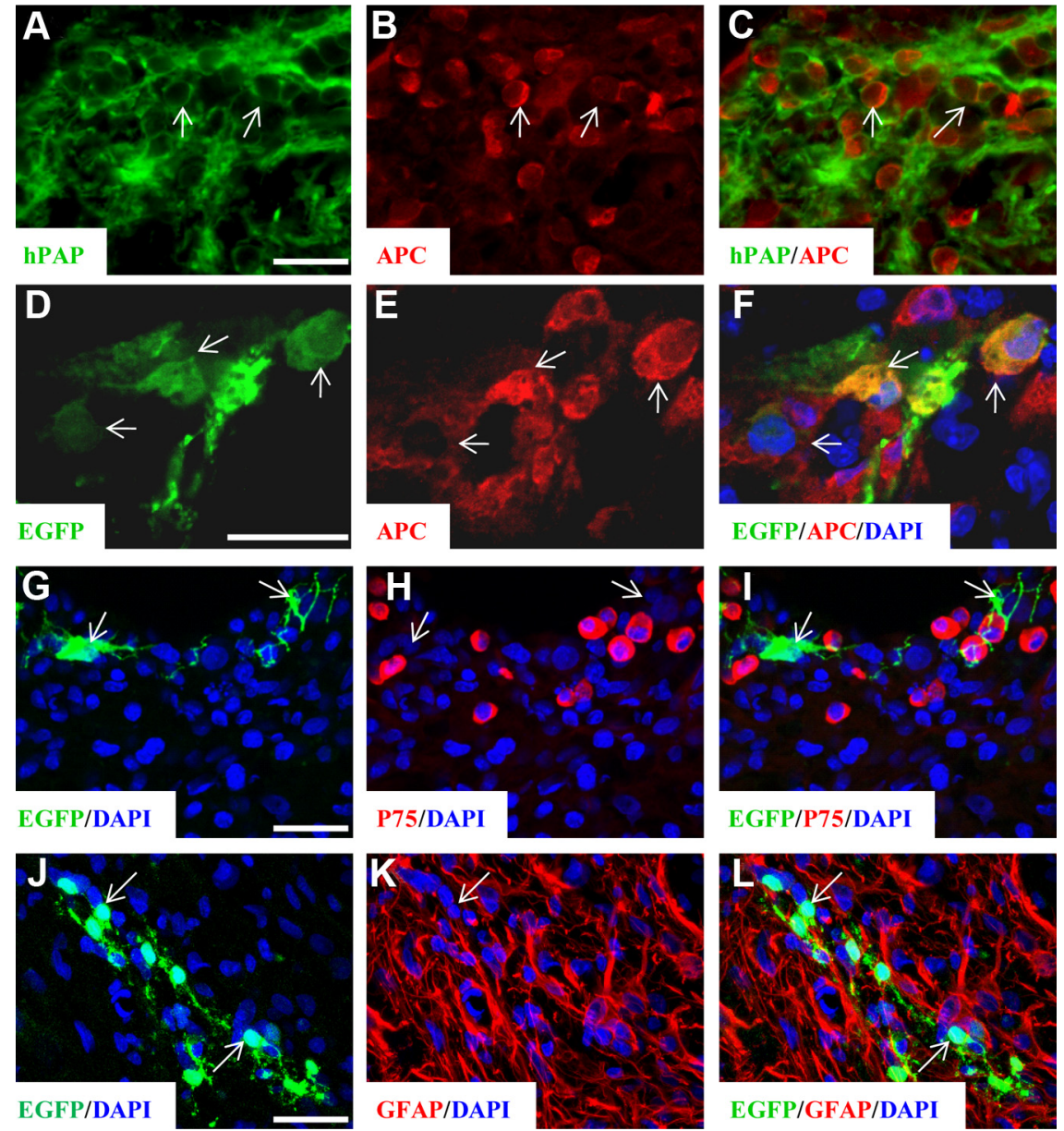

Figure 5. OL differentiation of transplanted OPCS after SCI. Two months after transplantation, many grafted CNTF-OPCS differentiated into $\mathrm{APC}{ }^{+}$mature $0 \mathrm{Ls}$ in the injured spinal cord $(\boldsymbol{A}-\boldsymbol{F})$. The grafted $\mathrm{hPAP}{ }^{+} \mathrm{OPC}$ s coexpressed the mature $0 \mathrm{~L}$ marker, APC, in their cytoplasm ( $\boldsymbol{A}-\boldsymbol{C}$, arrows). Similarly, the grafted OPCs identified by EGFP immunoreactivity in their cytoplasm also coexpressed APC (D-F, arrows). Although $75^{+}$Schwann cells were found in the contused spinal cord, Schwann cell differentiation of transplanted OPCs was not observed (G-I, arrows). The grafted OPCs also did not differentiate into GFAP ${ }^{+}$astrocytes, although gliosis, shown by GFAP immunoreactivity, was obvious in the injured spinal cord. Scale bars: $A-L, 20 \mu \mathrm{m}$.

3.4 times higher compared with $0.07 \mathrm{~mm}^{3}$ in EGFP-OPC-grafted ones (Fig. $4 H$ ). The survival of grafted OPCs was significantly increased in CNTF-OPC grafts compared with EGFP-OPC grafts, indicating that the expression of CNTF promoted the survival of grafted OPCs in the injured spinal cord.

\section{Transplanted OPCs differentiate into OLs in the injured spinal cord}

The grafted OPCs were double-stained with hPAP or EGFP and one of these neural cell markers: APC (mature OLs), p75 (Schwann cells), GFAP (astrocytes), or NG2 (undifferentiated OPCs). Before transplantation, most OPCs expressed NG2 (Fig. 1), a marker of undifferentiated OPCs. However, the majority of the grafted cells lost their expression of NG2 (data not shown). The results suggest that most grafted OPCs have started to differentiate. Most grafted OPCs, identified by hPAP in their membranes, expressed APC in their cytoplasm (Fig. 5A-C, arrows). Since the grafted OPCs also expressed EGFP, we double stained for EGFP and APC. Both EGFP and APC labeled the cytoplasm, and their colocation was more clearly shown in Figure $5 D-F$. These results showed that majority of grafted OPCs, identified by either hPAP (Fig. $5 A-C$ ) or EGFP (Fig. 5D-F) immunohisto- chemistry, differentiated into OLs. We chose EGFP over hPAP to quantify the differentiated phenotypes of grafted OPCs since EGFP labeled mainly the cell body. The OL differentiation from EGFP- or CNTF-OPCs was 46 and 70\%, respectively. The percentage of OL differentiation from CNTF-OPCs was significantly higher than the control EGFP-OPCs ( $p<$ 0.05). Our previous study (Talbott et al., 2006) showed that adult OPCs differentiate into Schwann cells after transplantation into chemically demyelinated spinal cord. Moreover, another study reported that APC labeled Schwann cells in addition to OLs (McTigue et al., 2001). To directly detect whether grafted OPCs differentiate into Schwann cells, we examined the expression of p75 in the grafted OPCs. Although strong expression of p75 was observed in the Schwann cells of the nerve root and Schwann cells that invaded in the injured spinal cord (Fig. 5G-I), the grafted EGFP- or CNTF-OPCs did not express p75 (Fig. 5G-I, arrows). Previous studies showed that the microenvironment in the contused spinal cord induced grafted NSCs mainly to differentiate into astrocytes (Chow et al., 2000; Cao et al., 2001; Hofstetter et al., 2005). We addressed whether the grafted OPCs differentiated into astrocytes in the injured spinal cord by double staining the grafted OPCs with EGFP and GFAP. Gliosis, shown by the strong GFAP immunoreactivity, is evident in the injured spinal cord (Fig. $5 J-L$ ). However, grafted OPCs did not express GFAP, indicating no astrocyte differentiation. Our results indicated that adult OPCs mainly differentiated along mature OLs after transplantation into the injured spinal cord and that expression of CNTF significantly increased their OL differentiation.

To test the effects of grafted OPCs on the differentiation of endogenous OPCs after SCI, the endogenous OPCs were labeled by injection of BrdU for the first $5 \mathrm{~d}$ after contusion. Then the percentage of $\mathrm{BrdU}^{+}$cells that differentiated into $\mathrm{APC}^{+} \mathrm{OLs}$ in the white matter at the injury epicenter was quantified in animals receiving grafts of DMEM, EGFP-OPCs, or CNTF-OPCs at 1 week after transplantation. As shown in supplemental Figure 1 (available at www.jneurosci.org as supplemental material), OL differentiation from endogenous $\mathrm{BrdU}^{+}$cells was observed in animals receiving grafts of CNTF-OPCs $(A-D$, arrows), EGFP-OPCs ( $E-H$, arrows), or DMEM ( $I-K)$. However, the percentages of $\mathrm{BrdU}^{+}$cells that differentiate into $\mathrm{APC}^{+}$OLs were significantly higher in animals receiving grafts of CNTF-OPCs $(27.1 \pm 5.7)$ or EGFP-OPCs (22.7 \pm 8.8) compared with one receiving grafts of DMEM (14.7 \pm 4.3). The percentages in CNTF-OPC-grafted animals were also higher than EGFP-OPC-grafted animals. These results suggest that OL differentiation of endogenous OPCs was enhanced by transplantation of EGFP- or CNTF-OPCs. 
Transplanted OPCs remyelinate the demyelinated axons in the injured spinal cord

All grafted OPCs express hPAP in their membrane. Therefore, we used hPAP immunoreactivity to directly detect whether mature OLs derived from the grafted $\mathrm{hPAP}^{+}$OPCs would form a myelin sheath around axons in the injured spinal cord. We found that grafted $\mathrm{hPAP}^{+} \mathrm{OPC}$ differentiated into $\mathrm{APC}^{+} \mathrm{OLs}$ (Fig. 6A-C, arrowhead), which formed multiple rings around the $\mathrm{NFM}^{+}$axons evident in cross sections (Fig. 6A-C, arrows). Multiple rings were seen emerging from a cell body of a hPAP ${ }^{+} / \mathrm{APC}^{+} \mathrm{OL}$ (arrowhead). We further demonstrated that these $\mathrm{hPAP}^{+}$ rings around $\mathrm{NFM}^{+}$axons were $\mathrm{MBP}^{+}$ (Fig. 6D-F, arrows). The remyelination from the grafted $\mathrm{hPAP}^{+}$OPCs was more evident in longitudinal sections (Fig. 6GI). $\mathrm{NFM}^{+}$axons were clearly wrapped by the $\mathrm{hPAP}^{+}$processes, which were colabeled by MBP (Fig. 6G- $I$, arrows). We further confirmed the grafted OPC-derived OL remyelination by using immunoelectron microscopy. hPAP immunoreactivity was detected in the membrane of processes or cell bodies of the grafted cells in the injured spinal cord. The $\mathrm{hPAP}^{+}$cells showed ultrastuctural characteristics of mature OLs, which sent their processes to wrap multiple axons close to them (Fig. 7A). The hPAP immunoreactivity was directly detected in myelin at higher magnifications (Fig. $7 B, C$ ), indicating remyelination derived from grafted OPCs.

The remyelination was further quantified on the toluidine blue-stained $1 \mu \mathrm{m}$ semithin cross sections of the transplanted spinal cord by using high-precision design-based unbiased systematic random sampling technique. OL- or SC-remyelinated axons were readily distinguished under high magnification (Fig. $7 D$ ). OL-remyelinated axons (Fig. $7 D$, arrows) were identified by their characteristically thin myelin sheaths relative to the diameter of the axons, with a myelin sheath thickness ranging from 0.1 to $0.4 \mu \mathrm{m}$ (Hildebrand and Hahn, 1978; Guy et al., 1989; Keirstead et al., 2005). Schwann cell-remyelinated axons (Fig. 7D, arrowheads) were identified by their characteristically thick myelin sheaths relative to axon diameter, with myelin sheath thickness ranging from 0.6 to $1.2 \mu \mathrm{m}$, their darker myelin staining relative to OL myelin, and the presence of a cell body immediately juxtaposed to the myelin sheath (Hildebrand and Hahn, 1978; Gilson and Blakemore, 2002; Keirstead et al., 2005). We counted OL- or SC-remyelinated axons in the VLF and LF of spinal cord at the injured epicenter. The number of OL-remyelinated axons was $10,898,6912,3898,3625$, and 3513, respectively, in the VLF at the injury epicenter of spinal cords that received the grafts of CNTFOPCs, EGFP-OPCs, CNTF-FBs, EGFP-FBs, or DMEM (Fig. 7E). The number of OL-remyelinated axons in the CNTF-OPCgrafted group is significantly higher than all other groups $(p<$ $0.001)$. The number of OL-remyelinated axons in all other groups was not statistically different, although the EGFP-OPC-grafted group had more OL-remyelinated axons than other three groups. The number of OL-remyelinated axons in the LF of the epicenter of the injured spinal cords that received the grafts of CNTFOPCs, EGFP-OPCs, CNTF-FBs, EGFP-FBs, or DMEM was
$42,739,25,382,14,704,13,493$, and 12,957, respectively. The CNTF-OPC-grafted animals had significant more remyelinated axons in LF than all other groups $(p<0.01)$. The EGFP-OPCgrafted animals also had significant more OL remyelination than animals receiving CNTF-FBs, EGFP-FBs, or control DMEM. The number of Schwann cell-remyelinated axons in either VLF or LF were not significantly different among five groups (Fig. $7 F$ ).

\section{Electrophysiological and locomotor functional recovery after transplantation of adult OPCs}

We next asked whether the increased remyelination by OPC transplantation could restore electrophysiological conduction. Previous studies showed that tcMMEP and MIER responses provided a reproducible, noninvasive, and objective assessment of axonal conduction and functional integrity in the descending VLF and intersegmental LF motor pathways, respectively, in both normal and injured spinal cord (Fehlings et al., 1987; Loy et al., 2002; Beaumont et al., 2006). We used these responses to monitor the electrophysiological function of VLF and LF axons after grafting. In the normal adult rat, the latency of the monosynaptic tcMMEP response was $6.2 \pm 0.3 \mathrm{~ms}$ and the amplitudes of this normal response ranged from 9.0 to $21.0 \mathrm{mV}$ with an average of $16.0 \pm 3.8 \mathrm{mV}$ (Loy et al., 2002; Cao et al., 2005a). After a 150 kdyn contusive SCI, tcMMEP responses disappeared (Fig. 8A). One week after transplantation of CNTF-OPCs, tcMMEP responses were partially restored in 6 of 10 rats (Fig. $8 \mathrm{~A}$ ); however, the latencies $(8.03 \pm 0.26 \mathrm{~ms})$ were significantly longer $(p<$ $0.001)$ and the amplitudes $(0.75 \pm 0.47 \mathrm{mv})$ were significantly smaller $(p<0.001)$ than in normal animals (Fig. $8 B, C)$. The latencies of tcMMEP responses in CNTF-OPC-transplanted animals continued to become shorter over time (Fig. $8 \mathrm{~B}$ ). The latencies at 3 weeks after graft, $6.35 \pm 0.66 \mathrm{~ms}$, were significantly shorter compared with week 1 after graft $(p<0.01)$ but still significantly longer than the latencies in normal animals. At week 

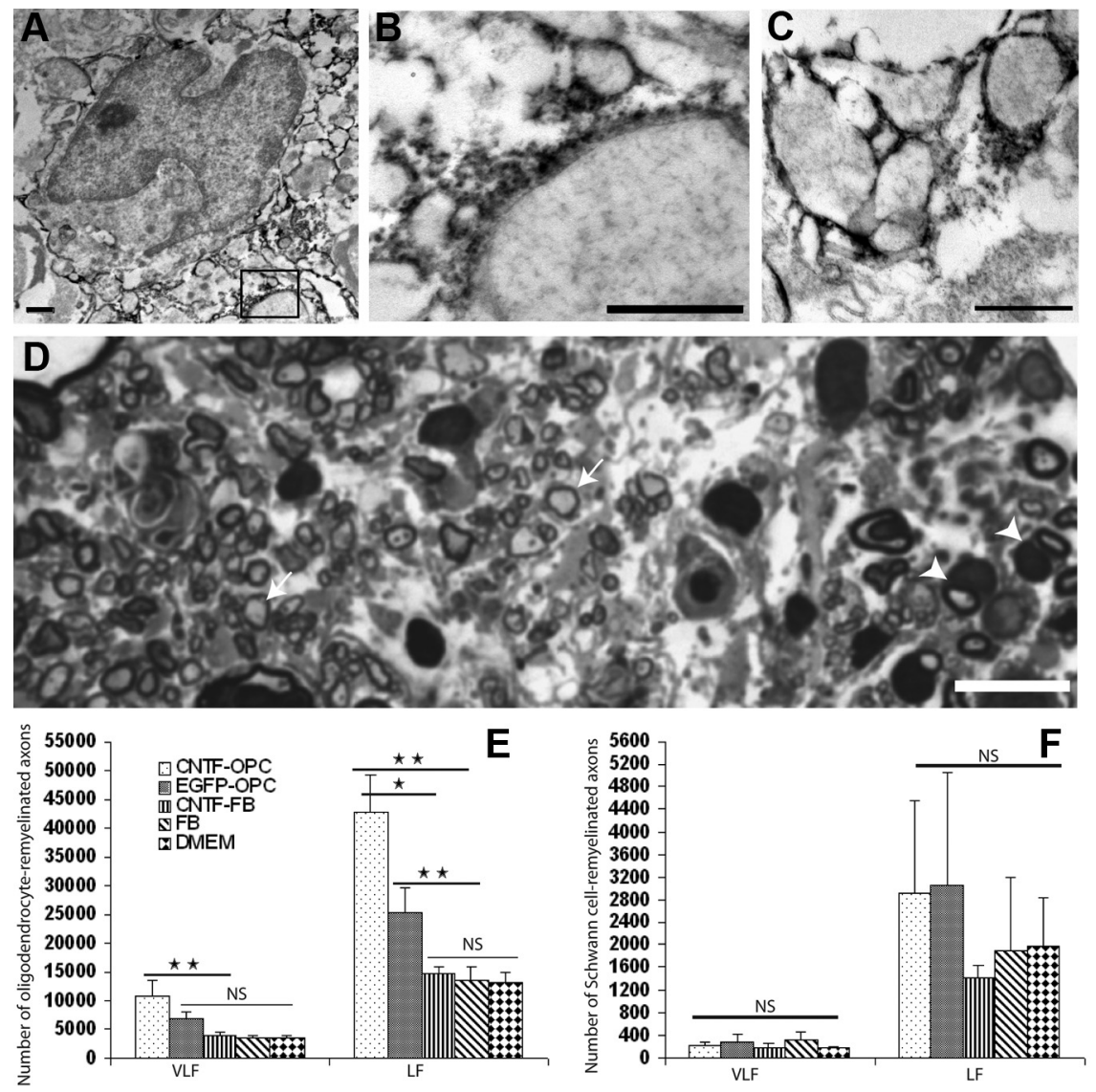

Figure 7. CNTF increased the number of OL-remyelinated axons by grafted OPCS after SCl. Immuno-EM confirmed that OLs from grafted OPCs, as shown by hPAP immunoreactivity, formed myelin on multiple axons $(A)$. At higher magnification (the box in $A$ is shown in $B$ ), it is evident that DAB reaction product of $\mathrm{PAP}$ immunoreactivity is found with the myelin surrounding one of the axons $(B, C$, indicating that these myelin sheaths were derived from grafted OPCS. OL- ( $\boldsymbol{D}$, arrows) and Schwann cell-remyelinated axons ( $\boldsymbol{D}$, arrowheads) were readily distinguished in the thin plastic section of spinal cord stained with toluidine blue. The OL-remyelinated axons $(\boldsymbol{E})$, but not SCremyelinated axons $(\boldsymbol{F})$, significantly increased in both VLF and LF at the injury epicenter in rats with grafts of OPCs or CNTF-OPCs. Data in $\boldsymbol{E}$ and $\boldsymbol{F}$ represent the mean \pm SD $(n=6) .{ }^{\star} p<0.05 ;{ }^{\star} p<0.01$. Scale bar: $\boldsymbol{A}-\boldsymbol{C}, 1 \mu \mathrm{m} ; \boldsymbol{D}, 10 \mu \mathrm{m}$.

5 after grafting, the latencies dropped to $5.84 \pm 0.39 \mathrm{~ms}$, which were significantly shorter than at weeks 1 and 3 after grafting (all $p<0.05)$, but were not significantly different from normal animals $(p>0.05)$. The mean amplitudes of the returned tcMMEP were also significantly increased over time (Fig. $8 C$ ). The amplitudes at week 3 and 5 weeks after graft, $2.0 \pm 1.9$ and $4.33 \pm 1.3$, respectively, were significantly higher than at week 1 after graft, $0.75 \pm 0.47$ (all $p<0.01$ ). The tcMMEP responses were also partially recovered in 2 of 10 rats receiving EGFP-OPC grafts from 1 week to 5 weeks after graft. In the animals that received DMEM, EGFP-FBs, or CNTF-FBs, the return of tcMMEP responses was not observed (data not shown). MIER responses were also conducted at 7 weeks after graft. Animals with recovered MIER responses were 2, 3, 2, 4, and 8 of 10 in groups that received grafts of DMEM, EGFP-FBs, CNTF-FBs, EGFP-OPCs, or CNTF-OPCs, respectively (Fig. $8 D$ ). The latencies of recovered MIER responses in CNTF-OPC-grafted animals were $6.6 \pm$ $0.24 \mathrm{~ms}$, which were significantly longer than in the normal rats $(5.44 \pm 0.61)$ (Fig. $8 E$ ). The amplitudes of the recovered MIER responses $(2.13 \pm 1.99)$ were significantly smaller than normal $(6.65 \pm 0.22)$ (Fig. $8 E)$. Our results showed that transplantation of CNTF-OPCs significantly increased the animals' tcMMEP and MIER responses, indicating that the conduction of the initially demyelinated axons in the VLF and LF was partially restored.
We further asked whether the electrophysiological restoration of tcMMEP and MIER responses correlated with improvement of hindlimb locomotor function. Locomotor function assessed by the BBB locomotor scores significantly improved over time in each group (Fig. 9A). BBB scores were significantly higher at weeks $4-7(p<0.01)$ than at week 1 after injury in all five groups. More importantly, CNTF-OPC-grafted animals exhibited significantly higher BBB locomotor scores than those receiving DMEM, EGFP-FBs, or CNTF-FBs at 3-7 weeks after injury (all $p<0.05)$. BBB scores in EGFP-OPCgrafted animals were also significantly higher than these three groups at 5-7 weeks after injury (all $p<0.05$ ). Although there was a trend for greater improvement of BBB scores in CNTF-OPC-grafted animals over EGFP-OPC-grafted ones from 3 to 7 weeks after injury, this improvement was not statistically significant. BBB scores among the five groups were not significantly different at 1 week after injury and before transplantation or at 2 weeks after injury and 1 week after transplantation. The BBB locomotor function scores were not significantly different among animals receiving DMEM, EGFP-FBs, or CNTF-FBs at all tested time points. Therefore, our behavioral results showed that transplantation of CNTF- or EGFP-OPCs significantly improved the hindlimb locomotor functions after SCI. To further investigate the relationship of remyelination and locomotion functional recovery, we asked whether the number of OL-remyelinated axons in the injured spinal cord correlated with BBB scores. As shown in Figure 9, $B$ and $C$, the OLremyelinated axons in the LF and VLF in the injury epicenter from animals of all groups were closely correlated with their BBB scores at 7 weeks after injury. The results suggest the direct contribution of OL remyelination to locomotion functional recovery.

\section{Discussion}

Differentiation of adult OPCs in the injured spinal cord

Multiple types of cells, including NSCs, glial-restricted precursors (GRPs), and OPCs, have been transplanted into the injured spinal cord (Enzmann et al., 2006; Coutts and Keirstead, 2008; Kulbatski et al., 2008; Louro and Pearse, 2008). Multipotent NSCs, isolated from fetal or adult CNS, mainly differentiate into astrocytes with a few $(<5 \%)$ into OL after transplantation into the injured spinal cord (Chow et al., 2000; Shihabuddin et al., 2000; Cao et al., 2001; Wu et al., 2002; Vroemen et al., 2003; Hofstetter et al., 2005). Approximately 15\% of grafted GRPs in the injured spinal cord differentiate into mature OLs (Cao et al., 2005b). In contrast, a much higher percentage (47\%) of grafted adult OPCs differentiate into mature OLs as shown in this study. Importantly, when xenografted to the forebrains of newborn shiver mice, OPCs from adult human subcortical white matter generate OLs more efficiently and ensheathed more host axons per donor cell than OPCs from 21- to 23-week-old fetal human 
forebrain (Windrem et al., 2004). Consistent with their findings, our results showed that adult OPC transplantation leads to faster locomotion recovery than their embryonic counterpart (Cao et al., 2005b). Furthermore, although adult spinal cord OPCs differentiate into type 2 astrocytes in medium containing serum or bone morphogenetic proteins (Cheng et al., 2007), transplanted adult OPCs either differentiate into mature OLs or remained undifferentiated in the injured spinal cord. These results are consistent with previous studies. Bipotential OPCs from neonatal optical nerve or brain differentiate along OL lineages without astrocyte commitment after transplantation into the adult demyelinated (Groves et al., 1993) or contused (Lee et al., 2005) spinal cord. Since astrocyte differentiation from grafted NSCs enhances the plasticity of pain fibers and promotes allodynia after SCI (Hofstetter et al., 2005), lack of astrocyte differentiation and concomitant allodynia plus its greatest potential for OL differentiation may make adult OPCs an ideal candidate for cell grafts to OL replacement and remyelination after SCI.

Successful OL differentiation and remyelination from engrafted OPCs raises the question of why endogenous remyelination is incomplete. OPCs persist in the normal adult spinal cord (Horner et al., 2000), and although the turnover of these cells is relatively low under normal conditions, their proliferation increases significantly after SCI (Ishii et al., 2001; McTigue et al., 2001; Yamamoto et al., 2001) or MS (Wolswijk, 1998, 2000). OL differentiation and remyelination from endogenous adult OPCs occur after CNS injuries (Gensert and Goldman, 1997; Zai and Wrathall, 2005; Tripathi and McTigue, 2007), but spontaneous remyelination is limited and incomplete after SCI. Electrophysiological experiments show persistent deficits of axonal conduction after SCI in humans (Alexeeva et al., 1997, 1998) and rodents (Blight, 1983; Talbott et al., 2005). Anatomical evidence also shows the demyelinated axons after acute and chronic SCI in both experimental animals and human (Bunge et al., 1993; Cao et al., 2005a; Guest et al., 2005; Totoiu and Keirstead, 2005). More recent data showed that demyelination after traumatic SCI is chronic and progressive. Although remyelinated axons do appear in the injured spinal cord, demyelinated axons are observed up to $450 \mathrm{~d}$ after injury (Totoiu and Keirstead, 2005). Surprisingly, the number of demyelinated axons increases in the chronic stage. A limited number of precursor cells, the presence of inhibitory factors for OL differentiation, and/or the lack of growth factors for OL survival and myelination in the injured CNS may all contribute to this failure of
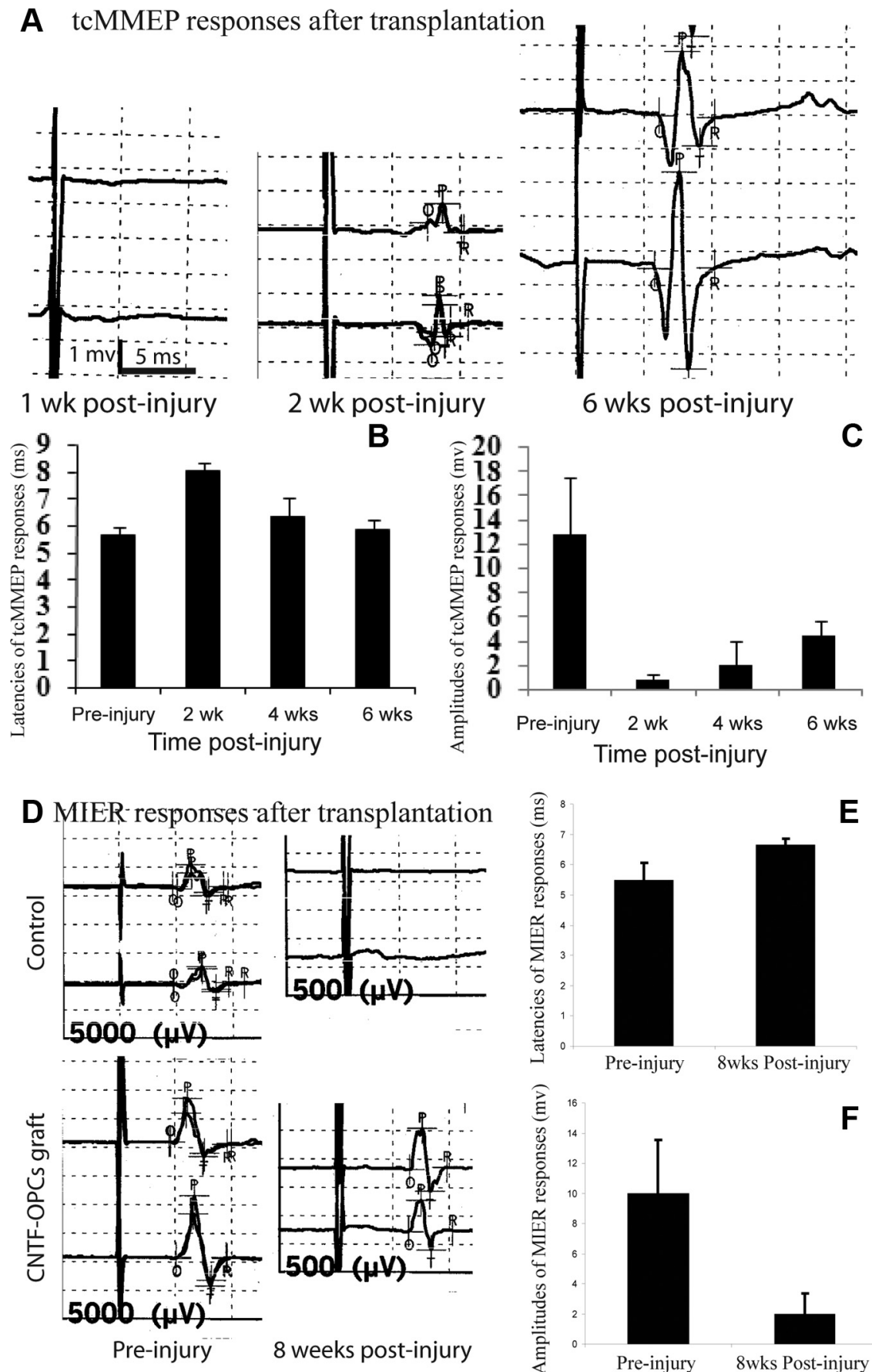

Figure 8. Electrophysiological recovery after transplantation of adult OPCS. Six of 10 animals receiving CNTF-adult OPC s showed recovery oftcMMEP responses compared with 2 of $10 \mathrm{in}$ OPC-grafted rats and none in animals receiving grafts of DMEM, $F B s$, or CNTF-FBs $(\boldsymbol{A})$. The latencies $(\boldsymbol{B})$ and amplitudes $(\boldsymbol{C})$ of recovered tcMMEP responses improved over time. The latencies at 4 and 6 weeks were significantly shorter than at 2 weeks after injury $(p<0.05)(B)$. The amplitudes at 6 weeks were also significantly higher than at 2 and 4 weeks after injury $(p<0.05)$ (C). Eight of 10 rats receiving CNTF-OPCs grafts showed recovery of MIER responses at 8 weeks after graft compared with 4 of 10 in OPC-grafted rats, and 2 of 10 in animals receiving DMEM, FBs, or CNTF-FBs $(\boldsymbol{D})$. The latencies $(\boldsymbol{E})$ and amplitudes $(\boldsymbol{F})$ of the recovered MIER responses in CNTF-OPC-grafted animals were significantly longer and small, respectively, than the baseline responses before injury (all $p<0.05)$. Quantitative data are the mean \pm SD $(n=6)$.

endogenous remyelination. Therefore, strategies to promote significant functional recovery after SCI by remyelination from endogenous NSCs or OPCs may be proven feasible once mechanisms regulating their proliferation, differentiation, and maturation are better understood. OPC transplantation is presently a more effective approach to enhance remyelination and locomotion functional recovery after SCI. 

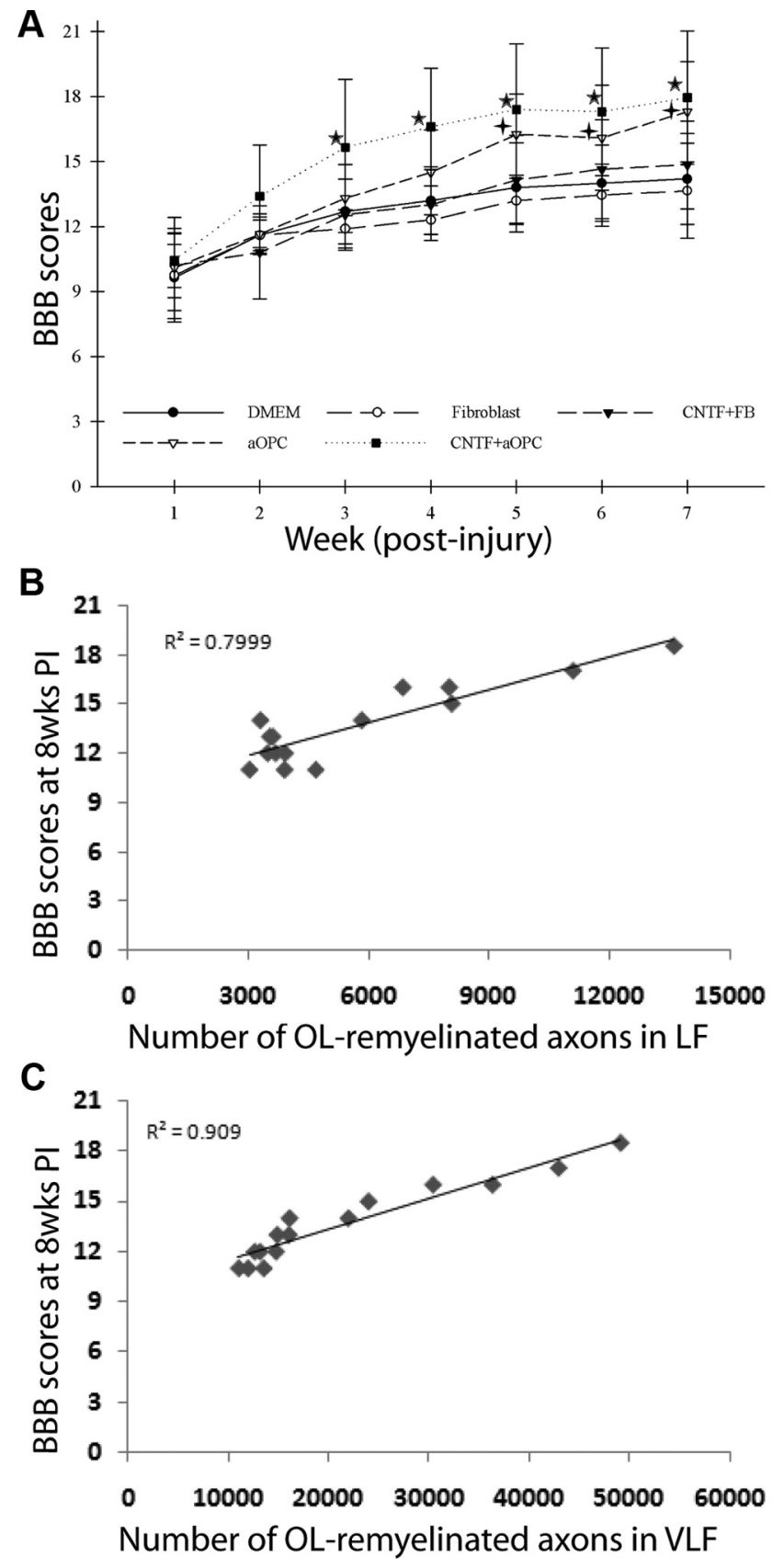

Figure 9. Hindlimb locomotor recovery after transplantation of adult OPCs. Locomotor function, determined using the BBB locomotor score, was significantly recovered in CNTF-OPCgrafted animals from weeks 3 to 7 after injury, and also in EGFP-OPC-grafted animals from weeks 5 to 7 after injury, compared with FB- or DMEM-grafted animals $(A)$ (data are mean \pm $\left.\mathrm{SD} ; n=10 ;{ }^{*} p<0.05\right)$. BBB scores were closely correlated with the number of OLremyelinated axons in both the $\operatorname{LF}(\boldsymbol{B})$ and $\operatorname{VLF}(\boldsymbol{C})$ at the injury epicenter of spinal cord.

\section{Oligodendrocyte survival is increased by CNTF}

CNTF promoted OL differentiation of adult OPCs in vitro (Fig. 2 ), consistent with previous studies of neonatal OPCs (Barres et al., 1996; Marmur et al., 1998). Also consistent with studies on neonatal OPCs (Barres et al., 1993), OLs newly differentiated from OPCs undergo apoptosis in defined culture medium without additional extracellular trophic support (Fig. 3). Addition of CNTF in the differentiation medium dramatically decreases OL apoptosis and supports their survival (Fig. 3). Among all tested growth/neurotrophic factors, CNTF is most effective factor for OL survival in vitro. CNTF also promoted OL differentiation of transplanted OPCs in the injured spinal cord from 47 to $70 \%$. In addition, the survival of the transplanted CNTF-expressing OPCs was threefold greater than control EGFP-OPCs (Fig. 4). Since the majority of grafted CNTF-expressing OPCs differentiate into mature OLs (Fig. 5), the dramatic survival effect of CNTF in grafted OPCs likely results from its protection of differentiated OLs. CNTF has previously shown to decrease the OL cell death and myelin loss as well as the severity of functional loss after experimental autoimmune encephalomyelitis (Butzkueven et al., 2002; Linker et al., 2002). More importantly, we show that combination of CNTF expression and OPC transplantation significantly increases the number of remyelinated axons in the injured spinal cord (Figs. 6, 7). CNTF may promote remyelination from grafted OPCs by increasing its OL differentiation and survival or/and directly enhancing its myelination. CNTF increases OL maturation and the expression of myelin proteins such as MBP and MOG (myelin oligodendrocyte glycoprotein) (Stankoff et al., 2002) and promotes myelination by OPCs when cocultured with dorsal root ganglion neurons (Ishibashi et al., 2006). These mechanisms may work synergistically to promote remyelination by grafted OPCs in the injured spinal cord. Delivery of CNTF alone is not enough to increase remyelination, since transplantation of CNTF-expressing fibroblasts did not increase the number of remyelinated axons in the injured spinal cord or enhance hindlimb locomotor recovery.

\section{Remyelination as a mechanism for SCI repair}

We provide strong evidence that enhancing remyelination by transplanted OPCs is an important mechanism for SCI repair. Transplanted OPCs predominantly differentiate into OLs, which form myelin around the axons in the injured spinal cord. Second, the number of OL-remyelinated axons is dramatically increased in both the VLF and LF of the injured spinal cord after OPC transplantation. Correspondingly, axonal conduction in the VLF and LF, detected by tcMMEP and MIER responses, respectively, is also significantly recovered. Third, the increased OL remyelination and electrophysiological restoration of tcMMEP and MIER responses are highly correlated with significant improvement of hindlimb locomotion. Finally, greater electrophysiological and locomotor recoveries are achieved after expression of $\mathrm{CNTF}$ in transplanted OPCs results in increasing OL differentiation and survival and more OL-remyelinated axons in the injured spinal cord. Importantly, the close correlation of BBB scores and the number of OL-remyelinated axons in both VLF and LF further support the importance of remyelination in SCI repair.

Our results indicate that OPC transplantation is an effective strategy for OL replacement and remyelination after traumatic SCI, consistent with previous studies using NSC (Cummings et al., 2005; Karimi-Abdolrezaee et al., 2006) or OPC grafts (Cao et al., 2005b; Keirstead et al., 2005). Our results also support the observation that remyelination by engrafted adult OPCs can restore axonal conduction, as evidenced by tcMMEP and MIER responses. These findings suggest that the demyelinated axons in the adult CNS can regain function if they are properly remyelinated (Bambakidis and Miller, 2004; Cao et al., 2005b; Lee et al., 2005). Previous studies have shown behavioral improvement after transplantation of NSCs or OPCs after SCI (Cao et al., 2005b; Hofstetter et al., 2005; Keirstead et al., 2005; Karimi-Abdolrezaee et al., 2006). Here, we more importantly demonstrate a direct correlation of remyelination and hindlimb locomotor recovery. In addition to cell replacement, transplanted stem cells or precursor cells can release soluble neurotrophic factors to promote axonal regeneration and sprouting and other constitutive repair 
after CNS injuries (Teng et al., 2002; Lu et al., 2003; Zhang et al., 2006). Although we cannot rule out the possibility that these "non-cell replacement" effects contribute to the locomotion recovery, the early recovery of electrophysiology and hindlimb locomotor function supported by histological evidence suggest remyelination is the major contributor to the observed recovery since functional recovery from successful axonal regeneration may take much longer, at least $>1$ month. The close correlation between the number of remyelinated axons and locomotor function underscores the importance of remyelination in behavioral improvement. It is possible that the regenerating axons and their subsequent remyelination could facilitate functional recovery in this experimental paradigm. However, the time course of recovery likely rules out regeneration as a major mechanism. Expression of CNTF dramatically increases OL differentiation and survival of and OL remyelination by grafted OPCs, which lead to greater electrophysiological and behavioral improvement. These results suggest that combinatorial strategies including delivery of growth factors and transplantation of stem cells is one effective approach for more optimal functional recovery after SCI (Bambakidis and Miller, 2004; Cao et al., 2005b; Karimi-Abdolrezaee et al., 2006).

\section{References}

Alexeeva N, Broton JG, Suys S, Calancie B (1997) Central cord syndrome of cervical spinal cord injury: widespread changes in muscle recruitment studied by voluntary contractions and transcranial magnetic stimulation. Exp Neurol 148:399-406.

Alexeeva N, Broton JG, Calancie B (1998) Latency of changes in spinal motoneuron excitability evoked by transcranial magnetic brain stimulation in spinal cord injured individuals. Electroencephalogr Clin Neurophysiol 109:297-303.

Bambakidis NC, Miller RH (2004) Transplantation of oligodendrocyte precursors and sonic hedgehog results in improved function and white matter sparing in the spinal cords of adult rats after contusion. Spine J $4: 16-26$.

Barbin G, Manthorpe M, Varon S (1984) Purification of the chick eye ciliary neuronotrophic factor. J Neurochem 43:1468-1478.

Barres BA, Schmid R, Sendnter M, Raff MC (1993) Multiple extracellular signals are required for long-term oligodendrocyte survival. Development 118:283-295.

Barres BA, Burne JF, Holtmann B, Thoenen H, Sendtner M, Raff MC (1996) Ciliary neurotrophic factor enhances the rate of oligodendrocyte generation. Mol Cell Neurosci 8:146-156.

Basso DM, Beattie MS, Bresnahan JC (1995) A sensitive and reliable locomotor rating scale for open field testing in rats. J Neurotrauma 12:1-21.

Beaumont E, Onifer SM, Reed WR, Magnuson DS (2006) Magnetically evoked inter-enlargement response: an assessment of ascending propriospinal fibers following spinal cord injury. Exp Neurol 201:428-440.

Blight AR (1983) Axonal physiology of chronic spinal cord injury in the cat: intracellular recording in vitro. Neuroscience 10:1471-1486.

Blight AR (1993) Remyelination, revascularization, and recovery of function in experimental spinal cord injury. Adv Neurol 59:91-104.

Bunge RP, Puckett WR, Becerra JL, Marcillo A, Quencer RM (1993) Observations on the pathology of human spinal cord injury. A review and classification of 22 new cases with details from a case of chronic cord compression with extensive focal demyelination. Adv Neurol 59:75-89.

Butzkueven H, Zhang JG, Soilu-Hanninen M, Hochrein H, Chionh F, Shipham KA, Emery B, Turnley AM, Petratos S, Ernst M, Bartlett PF, Kilpatrick TJ (2002) LIF receptor signaling limits immune-mediated demyelination by enhancing oligodendrocyte survival. Nat Med 8:613-619.

Cao Q, Zhang YP, Iannotti C, DeVries WH, Xu XM, Shields CB, Whittemore SR (2005a) Functional and electrophysiological changes after graded traumatic spinal cord injury in adult rat. Exp Neurol 191 [Suppl 1]:S3-S16.

Cao Q, Xu XM, Devries WH, Enzmann GU, Ping P, Tsoulfas P, Wood PM, Bunge MB, Whittemore SR (2005b) Functional recovery in traumatic spinal cord injury after transplantation of multineurotrophin-expressing glial-restricted precursor cells. J Neurosci 25:6947-6957.
Cao QL, Zhang YP, Howard RM, Walters WM, Tsoulfas P, Whittemore SR (2001) Pluripotent stem cells engrafted into the normal or lesioned adult rat spinal cord are restricted to a glial lineage. Exp Neurol 167:48-58.

Cao QL, Benton RL, Whittemore SR (2002a) Stem cell repair of central nervous system injury. J Neurosci Res 68:501-510.

Cao QL, Howard RM, Dennison JB, Whittemore SR (2002b) Differentiation of engrafted neuronal-restricted precursor cells is inhibited in the traumatically injured spinal cord. Exp Neurol 177:349-359.

Casley-Smith JR (1988) Expressing stereological results "per $\mathrm{cm}^{3 \text { " }}$ is not enough. J Pathol 156:263-265.

Chang A, Nishiyama A, Peterson J, Prineas J, Trapp BD (2000) NG2positive oligodendrocyte progenitor cells in adult human brain and multiple sclerosis lesions. J Neurosci 20:6404-6412.

Cheng X, Wang Y, He Q, Qiu M, Whittemore SR, Cao Q (2007) Bone morphogenetic protein signaling and olig $1 / 2$ interact to regulate the differentiation and maturation of adult oligodendrocyte precursor cells. Stem Cells 25:3204-3214.

Chow SY, Moul J, Tobias CA, Himes BT, Liu Y, Obrocka M, Hodge L, Tessler A, Fischer I (2000) Characterization and intraspinal grafting of EGF/ bFGF-dependent neurospheres derived from embryonic rat spinal cord. Brain Res 874:87-106.

Coggeshall RE, Lekan HA (1996) Methods for determining numbers of cells and synapses: a case for more uniform standards of review. J Comp Neurol 364:6-15.

Coutts M, Keirstead HS (2008) Stem cells for the treatment of spinal cord injury. Exp Neurol 209:368-377.

Crowe MJ, Bresnahan JC, Shuman SL, Masters JN, Beattie MS (1997) Apoptosis and delayed degeneration after spinal cord injury in rats and monkeys. Nat Med 3:73-76.

Cummings BJ, Uchida N, Tamaki SJ, Salazar DL, Hooshmand M, Summers R, Gage FH, Anderson AJ (2005) Human neural stem cells differentiate and promote locomotor recovery in spinal cord-injured mice. Proc Natl Acad Sci U S A 102:14069-14074.

Dusart I, Marty S, Peschanski M (1992) Demyelination, and remyelination by Schwann cells and oligodendrocytes after kainate-induced neuronal depletion in the central nervous system. Neuroscience 51:137-148.

Enzmann GU, Benton RL, Talbott JF, Cao Q, Whittemore SR (2006) Functional considerations of stem cell transplantation therapy for spinal cord repair. J Neurotrauma 23:479-495.

Fehlings MG, Tator CH, Linden RD, Piper IR (1987) Motor evoked potentials recorded from normal and spinal cord-injured rats. Neurosurgery 20:125-130.

Gensert JM, Goldman JE (1997) Endogenous progenitors remyelinate demyelinated axons in the adult CNS. Neuron 19:197-203.

Gilson JM, Blakemore WF (2002) Schwann cell remyelination is not replaced by oligodendrocyte remyelination following ethidium bromide induced demyelination. Neuroreport 13:1205-1208.

Gledhill RF, Harrison BM, McDonald WI (1973) Demyelination and remyelination after acute spinal cord compression. Exp Neurol 38:472-487.

Groves AK, Barnett SC, Franklin RJ, Crang AJ, Mayer M, Blakemore WF, Noble M (1993) Repair of demyelinated lesions by transplantation of purified O-2A progenitor cells. Nature 362:453-455.

Guest JD, Hiester ED, Bunge RP (2005) Demyelination and Schwann cell responses adjacent to injury epicenter cavities following chronic human spinal cord injury. Exp Neurol 192:384-393.

Guy J, Ellis EA, Kelley K, Hope GM (1989) Spectra of G ratio, myelin sheath thickness, and axon and fiber diameter in the guinea pig optic nerve. J Comp Neurol 287:446-454.

Hagg T, Varon S (1993) Ciliary neurotrophic factor prevents degeneration of adult rat substantia nigra dopaminergic neurons in vivo. Proc Natl Acad Sci U S A 90:6315-6319.

Hildebrand C, Hahn R (1978) Relation between myelin sheath thickness and axon size in spinal cord white matter of some vertebrate species. J Neurol Sci 38:421-434.

Hofstetter CP, Holmström NA, Lilja JA, Schweinhardt P, Hao J, Spenger C, Wiesenfeld-Hallin Z, Kurpad SN, Frisén J, Olson L (2005) Allodynia limits the usefulness of intraspinal neural stem cell grafts; directed differentiation improves outcome. Nat Neurosci 8:346-353.

Horner PJ, Power AE, Kempermann G, Kuhn HG, Palmer TD, Winkler J, Thal LJ, Gage FH (2000) Proliferation and differentiation of progenitor cells throughout the intact adult rat spinal cord. J Neurosci 20:2218-2228. Ishibashi T, Dakin KA, Stevens B, Lee PR, Kozlov SV, Stewart CL, Fields RD 
(2006) Astrocytes promote myelination in response to electrical impulses. Neuron 49:823-832.

Ishii K, Toda M, Nakai Y, Asou H, Watanabe M, Nakamura M, Yato Y, Fujimura Y, Kawakami Y, Toyama Y, Uyemura K (2001) Increase of oligodendrocyte progenitor cells after spinal cord injury. J Neurosci Res 65:500-507.

Itoyama Y, Webster HD, Richardson EP Jr, Trapp BD (1983) Schwann cell remyelination of demyelinated axons in spinal cord multiple sclerosis lesions. Ann Neurol 14:339-346.

Karimi-Abdolrezaee S, Eftekharpour E, Wang J, Morshead CM, Fehlings MG (2006) Delayed transplantation of adult neural precursor cells promotes remyelination and functional neurological recovery after spinal cord injury. J Neurosci 26:3377-3389.

Keirstead HS, Nistor G, Bernal G, Totoiu M, Cloutier F, Sharp K, Steward O (2005) Human embryonic stem cell-derived oligodendrocyte progenitor cell transplants remyelinate and restore locomotion after spinal cord injury. J Neurosci 25:4694-4705.

Kinsella TM, Nolan GP (1996) Episomal vectors rapidly and stably produce high-titer recombinant retrovirus. Hum Gene Ther 7:1405-1413.

Kocsis JD, Akiyama Y, Radtke C (2004) Neural precursors as a cell source to repair the demyelinated spinal cord. J Neurotrauma 21:441-449.

Kulbatski I, Mothe AJ, Parr AM, Kim H, Kang CE, Bozkurt G, Tator CH (2008) Glial precursor cell transplantation therapy for neurotrauma and multiple sclerosis. Prog Histochem Cytochem 43:123-176.

Lee KH, Yoon DH, Park YG, Lee BH (2005) Effects of glial transplantation on functional recovery following acute spinal cord injury. J Neurotrauma 22:575-589.

Li GL, Farooque M, Holtz A, Olsson Y (1999) Apoptosis of oligodendrocytes occurs for long distances away from the primary injury after compression trauma to rat spinal cord. Acta Neuropathol 98:473-480.

Linker RA, Mäurer M, Gaupp S, Martini R, Holtmann B, Giess R, Rieckmann P, Lassmann H, Toyka KV, Sendtner M, Gold R (2002) CNTF is a major protective factor in demyelinating CNS disease: a neurotrophic cytokine as modulator in neuroinflammation. Nat Med 8:620-624.

Liu XZ, Xu XM, Hu R, Du C, Zhang SX, McDonald JW, Dong HX, Wu YJ, Fan GS, Jacquin MF, Hsu CY, Choi DW (1997) Neuronal and glial apoptosis after traumatic spinal cord injury. J Neurosci 17:5395-5406.

Louis JC, Magal E, Takayama S, Varon S (1993) CNTF protection of oligodendrocytes against natural and tumor necrosis factor-induced death. Science 259:689-692

Louro J, Pearse DD (2008) Stem and progenitor cell therapies: recent progress for spinal cord injury repair. Neurol Res 30:5-16.

Loy DN, Magnuson DS, Zhang YP, Onifer SM, Mills MD, Cao QL, Darnall JB, Fajardo LC, Burke DA, Whittemore SR (2002) Functional redundancy of ventral spinal locomotor pathways. J Neurosci 22:315-323.

Lu P, Jones LL, Snyder EY, Tuszynski MH (2003) Neural stem cells constitutively secrete neurotrophic factors and promote extensive host axonal growth after spinal cord injury. Exp Neurol 181:115-129.

Marmur R, Kessler JA, Zhu G, Gokhan S, Mehler MF (1998) Differentiation of oligodendroglial progenitors derived from cortical multipotent cells requires extrinsic signals including activation of gp130/LIF $\beta$ receptors. J Neurosci 18:9800-9811.

McTigue DM, Wei P, Stokes BT (2001) Proliferation of NG2-positive cells and altered oligodendrocyte numbers in the contused rat spinal cord. J Neurosci 21:3392-3400.

Nashmi R, Fehlings MG (2001) Changes in axonal physiology and morphology after chronic compressive injury of the rat thoracic spinal cord. Neuroscience 104:235-251.

Nashmi R, Jones OT, Fehlings MG (2000) Abnormal axonal physiology is associated with altered expression and distribution of Kv1.1 and Kv1.2 $\mathrm{K}^{+}$channels after chronic spinal cord injury. Eur J Neurosci 12:491-506.

Naumann T, Schnell O, Zhi Q, Kirsch M, Schubert KO, Sendtner M, Hofmann HD (2003) Endogenous ciliary neurotrophic factor protects GABAergic, but not cholinergic, septohippocampal neurons following fimbria-fornix transection. Brain Pathol 13:309-321.

Plant GW, Currier PF, Cuervo EP, Bates ML, Pressman Y, Bunge MB, Wood PM (2002) Purified adult ensheathing glia fail to myelinate axons under culture conditions that enable Schwann cells to form myelin. J Neurosci 22:6083-6091.

Raff MC, Miller RH, Noble M (1983) A glial progenitor cell that develops in vitro into an astrocyte or an oligodendrocyte depending on culture medium. Nature 303:390-396.
Roy NS, Wang S, Harrison-Restelli C, Benraiss A, Fraser RA, Gravel M, Braun PE, Goldman SA (1999) Identification, isolation, and promoter-defined separation of mitotic oligodendrocyte progenitor cells from the adult human subcortical white matter. J Neurosci 19:9986-9995.

Schmitz C, Hof PR (2000) Recommendations for straightforward and rigorous methods of counting neurons based on a computer simulation approach. J Chem Neuroanat 20:93-114.

Shihabuddin LS, Horner PJ, Ray J, Gage FH (2000) Adult spinal cord stem cells generate neurons after transplantation in the adult dentate gyrus. J Neurosci 20:8727-8735.

Stankoff B, Aigrot MS, Noël F, Wattilliaux A, Zalc B, Lubetzki C (2002) Ciliary neurotrophic factor (CNTF) enhances myelin formation: a novel role for CNTF and CNTF-related molecules. J Neurosci 22:9221-9227.

Storkebaum E, Lambrechts D, Dewerchin M, Moreno-Murciano MP, Appelmans S, Oh H, Van Damme P, Rutten B, Man WY, De Mol M, Wyns S, Manka D, Vermeulen K, Van Den Bosch L, Mertens N, Schmitz C, Robberecht W, Conway EM, Collen D, Moons L, et al. (2005) Treatment of motoneuron degeneration by intracerebroventricular delivery of VEGF in a rat model of ALS. Nat Neurosci 8:85-92.

Talbott JF, Loy DN, Liu Y, Qiu MS, Bunge MB, Rao MS, Whittemore SR (2005) Endogenous Nkx2.2+/Olig2+ oligodendrocyte precursor cells fail to remyelinate the demyelinated adult rat spinal cord in the absence of astrocytes. Exp Neurol 192:11-24.

Talbott JF, Cao Q, Enzmann GU, Benton RL, Achim V, Cheng XX, Mills MD, Rao MS, Whittemore SR (2006) Schwann cell-like differentiation by adult oligodendrocyte precursor cells following engraftment into the demyelinated spinal cord is BMP-dependent. Glia 54:147-159.

Teng YD, Lavik EB, Qu X, Park KI, Ourednik J, Zurakowski D, Langer R, Snyder EY (2002) Functional recovery following traumatic spinal cord injury mediated by a unique polymer scaffold seeded with neural stem cells. Proc Natl Acad Sci U S A 99:3024-3029.

Totoiu MO, Keirstead HS (2005) Spinal cord injury is accompanied by chronic progressive demyelination. J Comp Neurol 486:373-383.

Tripathi R, McTigue DM (2007) Prominent oligodendrocyte genesis along the border of spinal contusion lesions. Glia 55:698-711.

Vroemen M, Aigner L, Winkler J, Weidner N (2003) Adult neural progenitor cell grafts survive after acute spinal cord injury and integrate along axonal pathways. Eur J Neurosci 18:743-751.

Windrem MS, Roy NS, Wang J, Nunes M, Benraiss A, Goodman R, McKhann GM 2nd, Goldman SA (2002) Progenitor cells derived from the adult human subcortical white matter disperse and differentiate as oligodendrocytes within demyelinated lesions of the rat brain. J Neurosci Res 69:966-975.

Windrem MS, Nunes MC, Rashbaum WK, Schwartz TH, Goodman RA, McKhann G 2nd, Roy NS, Goldman SA (2004) Fetal and adult human oligodendrocyte progenitor cell isolates myelinate the congenitally dysmyelinated brain. Nat Med 10:93-97.

Wolswijk G (1998) Chronic stage multiple sclerosis lesions contain a relatively quiescent population of oligodendrocyte precursor cells. J Neurosci 18:601-609.

Wolswijk G (2000) Oligodendrocyte survival, loss and birth in lesions of chronic-stage multiple sclerosis. Brain 123:105-115.

Wolswijk G, Noble M (1989) Identification of an adult-specific glial progenitor cell. Development 105:387-400.

Wolswijk G, Riddle PN, Noble M (1991) Platelet-derived growth factor is mitogenic for O-2Aadult progenitor cells. Glia 4:495-503.

Wu S, Suzuki Y, Noda T, Bai H, Kitada M, Kataoka K, Nishimura Y, Ide C (2002) Immunohistochemical and electron microscopic study of invasion and differentiation in spinal cord lesion of neural stem cells grafted through cerebrospinal fluid in rat. J Neurosci Res 69:940-945.

Yamamoto S, Yamamoto N, Kitamura T, Nakamura K, Nakafuku M (2001) Proliferation of parenchymal neural progenitors in response to injury in the adult rat spinal cord. Exp Neurol 172:115-127.

Zai LJ, Wrathall JR (2005) Cell proliferation and replacement following contusive spinal cord injury. Glia 50:247-257.

Zhang SC, Ge B, Duncan ID (1999) Adult brain retains the potential to generate oligodendroglial progenitors with extensive myelination capacity. Proc Natl Acad Sci U S A 96:4089-4094.

Zhang YW, Denham J, Thies RS (2006) Oligodendrocyte progenitor cells derived from human embryonic stem cells express neurotrophic factors. Stem Cells Dev 15:943-952. 